\title{
Interaction of multiporphyrin systems with molecular oxygen in liquid solutions: extra-ligation and screening effects
}

\author{
Eugenii I. Sagun ${ }^{\mathrm{a}, *}$, Eduard I. Zenkevich ${ }^{\mathrm{a}}$, Valentin N. Knyukshto ${ }^{\text {a }}$, \\ Alexander M. Shulga ${ }^{a}$, Dzmitry A. Starukhin ${ }^{a}$, Christian von Borczyskowski ${ }^{b}$

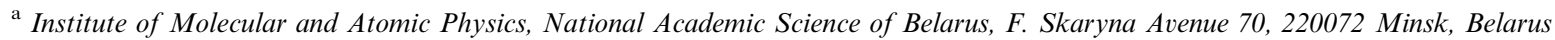 \\ b Institute of Physics, University of Technology Chemnitz, Reichenhainer Strasse 70, 09107 Chemnitz, Germany
}

Received 20 April 2001; in final form 12 September 2001

\begin{abstract}
Steady-state and time-resolved studies indicate that for a sequence of porphyrin or chlorin chemical dimers $\mathrm{Zn}$ cyclodimer $\rightarrow(\mathrm{ZnOEP})_{2} \mathrm{Ph} \rightarrow(\mathrm{ZnOEP})_{2} \rightarrow(\mathrm{ZnHTPP})_{2} \rightarrow(\mathrm{ZnOEChl})_{2}$ with relative lowering of excited $\mathrm{S}_{1}$ - and $\mathrm{T}_{1}$ states, the extra-ligation by pyridine (PYR) does not influence essentially on fluorescence parameters but leads to an increase of $T_{1}$-states non-radiative decay (the most pronounced for dimers with higher lying $T_{1}$-levels). For pyridinated dimers at $293 \mathrm{~K} \mathrm{~T}_{1}$-states quenching by molecular oxygen depends on the spacer flexibility and donor-acceptor interactions with PYR. In self-assembled triads and pentads energy and electron transfer (within a few ps) takes place from $\mathrm{Zn}$-dimers to pyridyl substituted porphyrin extra-ligand, $\mathrm{H}_{2} \mathrm{P}$, followed by the effective population of $\mathrm{H}_{2} \mathrm{P}_{1}$ state. For these systems, bimolecular constants of $\mathrm{H}_{2} \mathrm{P} \mathrm{T}_{1}$-states quenching by $\mathrm{O}_{2}$ decrease by 1.4-1.8 times with respect to those found for individual monomeric porphyrins. This effect is explained by the screening action of a strongly quenched $\mathrm{Zn}$-porphyrin dimer subunit limiting the access of oxygen molecule to the excited extra-ligand. (c) 2002 Elsevier Science B.V. All rights reserved.
\end{abstract}

Keywords: Porphyrin and chlorin dimers; Triads; Pentads; Extra-ligation; Screening; Excited states quenching by molecular oxygen

\section{Introduction}

At present, supramolecular chemistry is reaching highly elaborate levels of sophistication and the analysis of the co-operative behaviour of subunits within controlled spatial assemblies involving molecular recognition, catalysis, molecular devices, etc. In this respect, a non-covalent self-

\footnotetext{
${ }^{*}$ Corresponding author.
}

assembly based on the ligand coordination properties of metalloporphyrins ( $\mathrm{Zn}, \mathrm{Mg}, \mathrm{Co}, \mathrm{Fe}, \mathrm{Ni}$ ) seems to be an alternative way for the construction and investigation of a variety of artificial supramolecular systems with different geometry, spectral and photophysical characteristics [1-9]. Being studied in solutions at $77-293 \mathrm{~K}$, these coordinatively formed multiporphyrin arrays have shown efficient light-harvesting properties and light-driven intracomplex electron transfer. Recently, the preparation of ordered $\mathrm{Zn}$-porphyrin monolayers 
on solid surfaces has been pursued using non-covalent axial ligation bonding $[10,11]$. Such organothin films whose structure and orientation are precisely controlled via ligation interactions are expected to be applicable for molecular photoreactive optical devices.

The interest to $\mathrm{Zn}$-porphyrins that are often used for the formation of stable multimolecular systems is due to several reasons. Being tetra-coordinated in porphyrin ligand $\mathrm{Zn}$ central ion is capable to form penta-coordinated complexes through the addition of one extra-ligand only, while $\mathrm{Mg}$ - and $\mathrm{Fe}-$ porphyrins are characterised by a diversity of extra-liganded forms $[12,13]$. This property is very operative upon the formation of supramolecular systems with a desirable geometry $[6,14]$. Because of relatively high photostability and comparatively low one-electron oxidation potentials $\mathrm{Zn}$-porphyrins seem to be promising subunits for studying the photoinduced electron transfer in multimolecular assembles containing electron acceptors. It has been shown that the extra-coordination of $\mathrm{Zn}$-porphyrin moieties by pyridine (PYR) results in an essential increase in the rate constant for photoinduced-electrontransfer reactions in covalently linked diads [15] and triads [16]. In the case of diffusionally controlled electron transfer from the excited triplet state of $\mathrm{Zn}$-porphyrin to benzoquinone, the extraligation by PYR leads to the remarkable enhancement of quantum yields of the porphyrin cation radicals formation [17]. In contrast to Co-, $\mathrm{Fe}$-, Ni-complexes, $\mathrm{Zn}$-porphyrins are both fluorescing and phosphorescing (at $77 \mathrm{~K}$ ) species in solutions [18-20]. Thus, it is possible to carry out comparative studies of the extra-ligation influence on the deactivation of electronic $\mathrm{S}_{1}$ - and $\mathrm{T}_{1}$-states of multiporphyrin systems as well as the quenching of these excited states by molecular oxygen in liquid solutions.

In biological terms, the relatively facile ligand exchange reactions of zinc allow this ion to play a structural role in the interactions between the proteins and DNA macromolecules [21]. In addition, $\mathrm{Zn}$-complexes of tetrapyrrole compounds are widely used for the modelling sunlight energy collection and photoinduced charge separation taking place in natural photosynthetic objects with participation of chlorophyll molecules (Mg-complexes) [22-25]. Such an approach seems to be reasonable as far as the main spectral and photophysical properties of $\mathrm{Zn}$ - and corresponding $\mathrm{Mg}$ complexes do not differ significantly while $\mathrm{Zn}-$ porphyrins and $\mathrm{Zn}$-chlorins are relatively stable. In this respect, it should be mentioned that in many native protein complexes a tetrapyrrole macrocycle occupies four of the central metal's coordination sites. The remaining axial vacant positions of the metal are occupied either by substrate and reactant molecules or by amino acid side chains. In fact, such extra-ligation may determine architecture and structural properties of protein complexes. Besides, extra-ligation interactions can lead to changes of the porphyrin excitedstate and redox properties, thus affecting the efficiency of natural dark and photoinduced processes (catalysis of biochemical reactions, photoinduced charge separation in photosynthesis, generation of singlet oxygen in solutions and tissues, etc.).

The goal of the present work is the comparative study of the extra-ligation influence on the deactivation of $S_{1}$ - and $T_{1}$-states for various types of multiporphyrin systems as well as on their interaction with molecular oxygen in solutions.

In this respect, we have designed and synthesised a set of $\mathrm{Zn}$-porphyrin and $\mathrm{Zn}$-chlorin chemical dimers in which $\pi$-conjugated macrocycles are covalently linked via spacers of various nature and flexibility $\left(-\mathrm{CH}_{2}-\mathrm{CH}_{2}-\right.$ bond or phenyl ring in mesoposition and cyclodimers). Here we analysed how the axial extra-ligation by PYR affects on the photophysical properties of chemical dimers of tetrapyrrole compounds.

Next step includes the comparative investigation of the dimer excited $\mathrm{S}_{1}$ - and $\mathrm{T}_{1}$-states quenching by molecular oxygen in liquid solutions at room temperature with and without PYR admixture.

At last, multiporphyrin triads and pentads have been prepared via non-covalent binding interactions of Zn-porphyrin or Zn-chlorin chemical dimers with di- and tetrapyridyl containing porphyrin or chlorin extra-ligands according to an approach described in our previous papers $[6,16,26]$. Primary photophysical processes in these 
systems including energy transfer and photoinduced charge separation have been investigated by steady-state and time-resolved absorption and fluorescence spectroscopy [16,27-30]. Here, taking into account the last results we pay our attention on the peculiarities of the interaction of molecular oxygen with the triads and pentads of various and controlled geometry.

\section{Experimental}

\subsection{Synthesis and objects}

For the preparation of the chemical dimers, methods developed for the synthesis of mesosubstituted porphyrins and chlorins have been used. The synthesis, identification and purification of the dimers with phenyl spacer, 1,4-bis \{[zinc(II)]5-(2,3,7,8,12,13,17,18-octaethylporphyrinyl)\}benzene, $(\mathrm{ZnOEP})_{2} \mathrm{Ph}$, and 1,4-bis $\{$ zinc(II) $] 5-(10$, 15,20-tris( $p$-hexylphenyl)-porphyrinyl) $\}$ benzene, $(\mathrm{ZnHTPP})_{2}$, has been described in our earlier paper [26]. The synthesis, identification and purification of chemical dimers in which the monomer subunits are linked via mesoposition by a $-\mathrm{CH}_{2}-$ $\mathrm{CH}_{2}-$ group, 1,2-bis $\{5$ [zinc(II) octaethylporphyrinyl] $\}$ ethane, $(\mathrm{ZnOEP})_{2}$, and 1,2-bis $\{\gamma$-[zinc(II)octaethylchlorinyl]\} ethane, $(\mathrm{ZnOEChl})_{2}$, have been carried out according to methods presented in [31,32]. The synthesis and identification procedures for the chemical dimer of $\mathrm{Zn}$-cyclopentaneporphyrins, $\mathrm{Zn}-3^{\prime}, 3^{\prime}$-cyclodimer, have been described in our previous paper [33]. This dimer includes one $\mathrm{Zn}-3^{\prime}, 5^{\prime}$-cyclo-3'-methyl-2,7,8,12,13, 17,18-heptaethyl-22H,24H-porphyrin molecule and one $\mathrm{Zn}-3^{\prime}, 5^{\prime}$-cyclo-3'-exomethylene-2,7,8,12, 13,17,18-heptaethyl-22H,24H-porphyrin molecule. Absorption and fluorescence spectra as well as NMR an mass-spectroscopy data obtained for these five dimers have been described elsewhere [6,34,35]. Figs. 1 and 2 show these chemical dimers composed of $\mathrm{Zn}$-porphyrins and $\mathrm{Zn}$-chlorins monomeric subunits.

The formation of self-assembling porphyrin triads and pentads has been succeeded using twofold extra-ligation of both central $\mathrm{Zn}$ ions of the dimers with two nitrogens of mesopyridyl rings in the corresponding di- and tetrapyridyl containing free base porphyrin extra-ligands based on a "keyhole" principle [6,26,27]. All pyridyl containing monomeric porphyrins, $\mathrm{H}_{2} \mathrm{P}\left(m^{\wedge} \mathrm{Pyr}\right)_{2}$-(iso- $\left.\mathrm{PrPh}\right)_{2}$, $\mathrm{H}_{2} \mathrm{P}(m \text {-Pyr })_{2}$-(iso-PrPh $)_{2}, \mathrm{H}_{2} \mathrm{P}\left(p^{\wedge} \mathrm{Pyr}\right)_{2}(\mathrm{Ph})_{2}$ and $\mathrm{H}_{2} \mathrm{P}\left(p^{\wedge} \mathrm{Pyr}\right)_{4}$ (Fig. 2) used for complexation with the dimers $(\mathrm{ZnOEP})_{2} \mathrm{Ph}$ and $(\mathrm{ZnHTPP})_{2}$ have been synthesised and purified according to known methods [36,37]. The triads and pentads were formed at room temperature during a titration of the chemical dimer solution (concentration of $1-4 \times$ $10^{-6} \mathrm{M}$ ) with an extra-ligand solution (concentration of $\left.0.3-2 \times 10^{-4} \mathrm{M}\right)$. Absorption and fluorescence (excited at the isosbestic point observed in the absorption) spectra have been measured after each step of the titration procedure. The step, at which no further changes in absorption of the dimer were detected within experimental error, was considered as the final point of the titration procedure. The optimised (HYPERCHEM software, release 4, semiempirical method PM3) structures of multiporphyrin arrays under consideration are presented in Fig. 3.

Solvents (Aldrich spectroscopic grade), methylcyclohexane (MCH) and toluene (TOL) were additionally dried using molecular sieves, PYR, was used without further purification. Experiments at $77 \mathrm{~K}$ were performed in $\mathrm{MCH}$ rigid glassy solutions. For low-temperature experiments a home-made cryostat was used. TOL is non-ligating solvent. Correspondingly, non-polar TOL and $\mathrm{MCH}$ were used for the study of spectral-kinetic properties for non-ligated zinc(II) porphyrins and chlorins. The formation and investigation of ligated compounds were done in a $1 \%$ PYR in TOL or MCH solutions.

\subsection{Spectral and kinetic measurements}

Electronic absorption spectra were recorded on Shimadzu UV-3101PC and Cary 500 Scan spectrophotometers. The static fluorescence and excitation spectra were recorded on a Shimadzu RF-5001PC spectrofluorimeter. Corrected steadystate fluorescence and phosphorescence spectra at various temperatures were measured on a laboratory spectral-luminescent set-up, equipped with a personal computer. It is based on two grating 


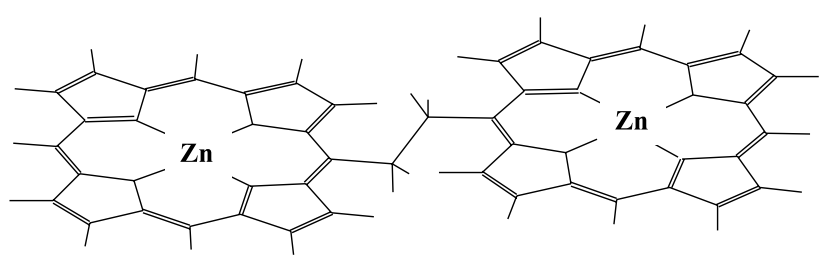

\section{$(\mathrm{ZnOEP})_{2}$}

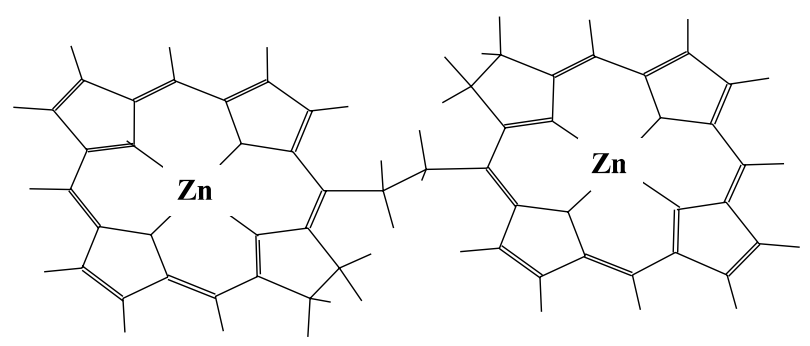

\section{$(\mathrm{ZnOEChl})_{2}$}

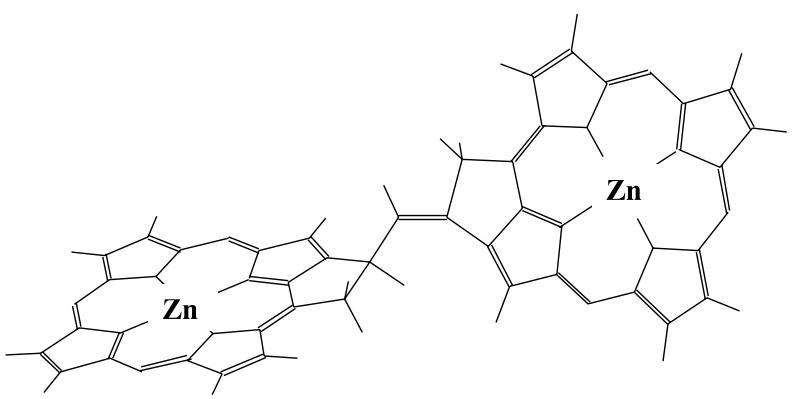

\section{$\mathbf{Z n}^{\prime} \mathbf{3}^{\prime}, \mathbf{3}^{\prime}$-cyclodimer}

Fig. 1. Structures of chemical dimers with a single $-\mathrm{CH}_{2}-\mathrm{CH}_{2}-$ bond between macrocycles, $(\mathrm{ZnOEP})_{2}$, $(\mathrm{ZnOEChl})_{2}$, and $\mathrm{Zn}-3^{\prime}, 3^{\prime}-$ cyclodimer where porphyrin monomers are linked via isocycles.

monochromators MDR-23. The operating spectral region was from 200 to $1100 \mathrm{~nm}$, and the exciting light sources were high pressure xenon lamp DKsSh-3000 with water cooling system xenon or an argon laser. Emission from the sample was modulated by disk modulator and then directed to recording monochromator. For better signal-tonoise ratio the experimental set-up was equipped with a thermocooling system for the photomultiplier (FEU-83 or FEU-100). The reproducibility of the system is $5 \%$, the accuracy of emission quantum yield $(\varphi)$ measurements is $5-7 \%$ for $\varphi \geqslant 0.1$, and the limit of emission quantum yields measured is $10^{-5}$. The fluorescence quantum yields $\varphi_{\mathrm{F}}$ of the systems under investigation were measured by the relative method, tetraphenylporphyrin in TOL $\left(\varphi_{\mathrm{F}}=0.09\right.$ at $293 \mathrm{~K}$ [38] $)$ was used as a standard.
The phosphorescence quantum yields $\varphi_{\mathrm{P}}$ at $77 \mathrm{~K}$ were obtained by comparison with the fluorescence quantum yields $\varphi_{\mathrm{F}}$ values for the same compound according to the formula

$\varphi_{\mathrm{Ph}}=\frac{S_{\mathrm{P}} \tau_{\mathrm{F}}(77 \mathrm{~K})}{S_{\mathrm{F}} \tau_{\mathrm{F}}(293 \mathrm{~K})} \varphi_{\mathrm{F}}(293 \mathrm{~K})$,

where $S_{\mathrm{P}}$ and $S_{\mathrm{F}}$ are the areas under the corrected quantum phosphorescence and fluorescence spectra, respectively, $\tau_{\mathrm{F}}$ is fluorescence lifetime. Phosphorescence decays were measured at $0-0$ bands maxima of phosphorescence spectra by the pulse method using the second harmonic of the YAG: $\mathrm{Nd}^{3+}$ pulse solid laser $\left(\lambda_{\mathrm{ex}}=532 \mathrm{~nm}\right.$, the experimental response $\Delta t_{1 / 2}=15 \mathrm{~ns}$ FWHM) for the excitation and the recording system based on monochromator, a photomultiplier FEU-83 and a 


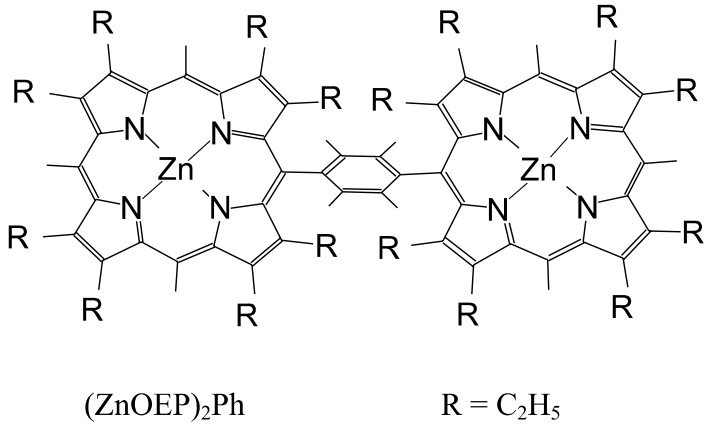

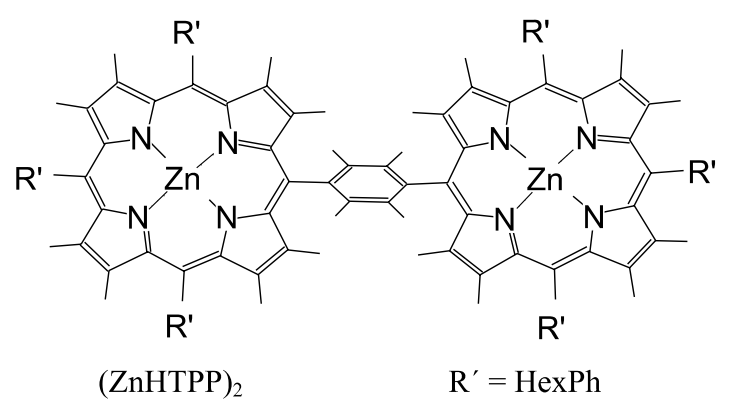

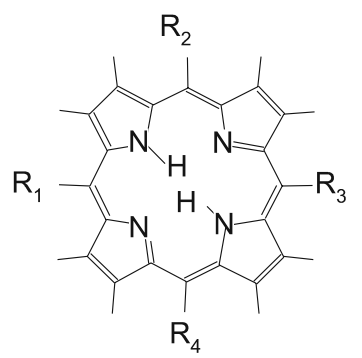

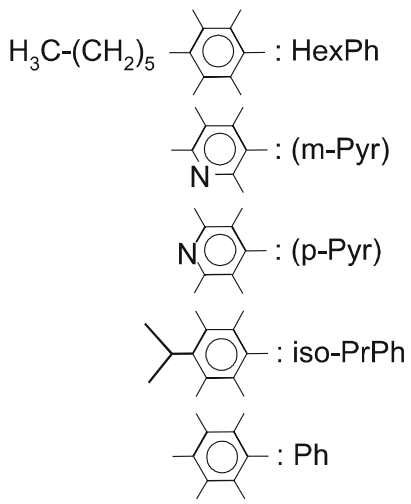

Fig. 2. Structures of chemical dimers with a phenyl spacer, $(\mathrm{ZnOEP})_{2} \mathrm{Ph},(\mathrm{ZnHTPP})_{2}$, and the pyridyl-containing monomeric porphyrins, $\mathrm{H}_{2} \mathrm{P}\left(m^{\wedge} \mathrm{Pyr}\right)_{2}$-(iso- $\left.\mathrm{PrPh}\right)_{2}, \mathrm{H}_{2} \mathrm{P}(m \text {-Pyr })_{2}$-(iso- $\left.\mathrm{PrPh}\right)_{2}, \mathrm{H}_{2} \mathrm{P}\left(p^{\wedge} \mathrm{Pyr}\right)_{2}(\mathrm{Ph})_{2}$ and $\mathrm{H}_{2} \mathrm{P}\left(p^{\wedge} \mathrm{Pyr}\right)_{4}$ used as extra-ligands upon the triad and pentad formation.

digital oscilloscope S9-27 equipped with a personal computer.

Fluorescence decays $\tau_{\mathrm{F}}$ were measured using a PRA-3000 pulse fluorometer operating in the single photon counting mode. In order to analyse multicomponent kinetics for the triads the time correlated single photon counting (TCSPC) experiments were performed. For excitation a vertical polarised dye laser (Spectra $\mathrm{Ar}^{+}$-Laser Mod. 171/Dye-Laser Mod. 343) with a repetition rate of $4 \mathrm{MHz}$ and pulses of $15 \mathrm{ps}$ FWHM was used. The fluorescence was detected via a polariser set at the magic angle $\left(54.7^{\circ}\right)$ with respect to the electric vector of the excitation light through a minimonochromator by a micro-channel plate. The system response was $\Delta t_{1 / 2}=75 \mathrm{ps}$. The corresponding software program (global analysis fit) was used for multidecay analysis with the minimisation of chi-square values $\chi^{2}$.

In liquid solutions at $293 \mathrm{~K}$, triplet state decays and quantum yields of singlet oxygen generation were measured using a laboratory experimental 

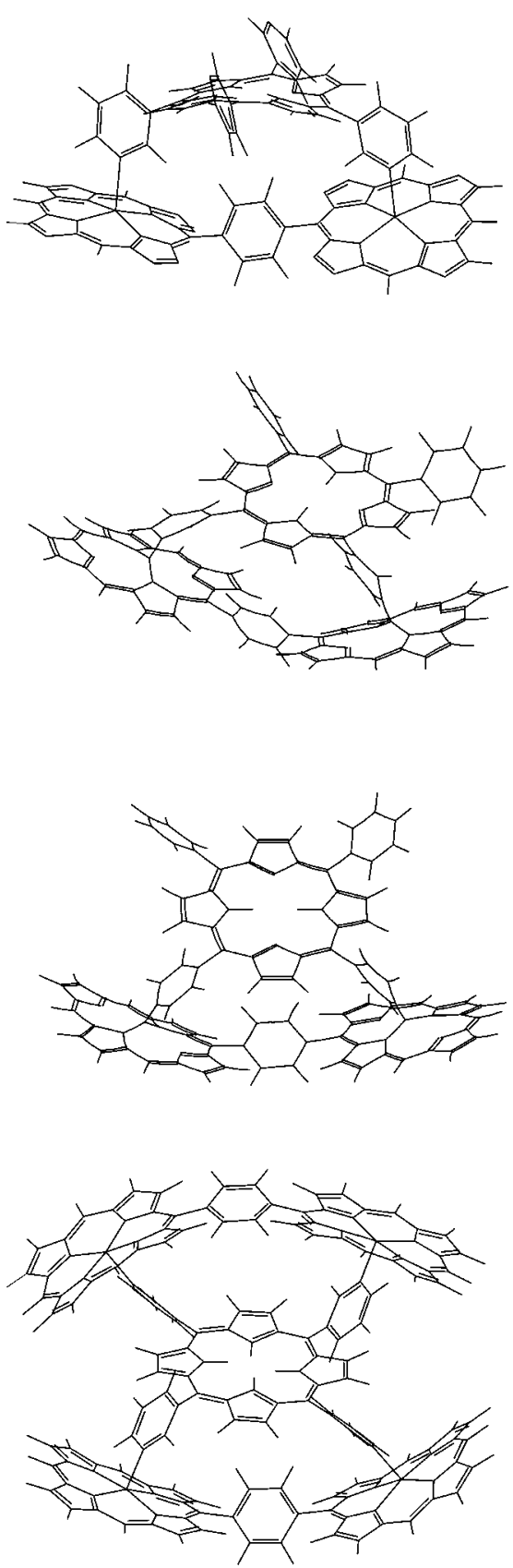

Triad with extra-ligand having opposite metapyridyl rings: $(\mathrm{m}-\mathrm{Pyr})_{2}$

\section{$(\mathrm{ZnHTPP})_{2} \otimes \mathrm{H}_{2} \mathrm{P}(\mathrm{m}-\mathrm{Pyr})_{2}$}

Triad with extra-ligand having adjacent metapyridyl rings: $\left(\mathrm{m}^{\wedge} \mathrm{Pyr}\right)_{2}$

$(\mathrm{ZnHTPP})_{2} \otimes \mathrm{H}_{2} \mathbf{P}\left(\mathrm{m}^{\wedge} \mathrm{Pyr}\right)_{2}$

$(\mathrm{ZnOEP})_{2} \mathrm{Ph} \otimes \mathrm{H}_{2} \mathrm{P}\left(\mathrm{m}^{\wedge} \mathrm{Pyr}\right)_{2}$

Triad with extra-ligand having adjacent parapyridyl rings: $\left(\mathrm{p}^{\wedge} \mathrm{Pyr}\right)_{2}$

$(\mathrm{ZnHTPP})_{2} \otimes \mathrm{H}_{2} \mathbf{P}\left(\mathbf{p}^{\wedge} \mathbf{P y r}\right)_{2}$

Pentad with extra-ligand having four meta-

pyridyl rings: $(\mathrm{m}-\mathrm{Pyr})_{4}$

\section{$2(\mathrm{ZnOEP})_{2} \mathrm{Ph} \otimes \mathrm{H}_{2} \mathrm{P}(\mathrm{m}-\mathrm{Pyr})_{4}$}

Fig. 3. Mutual arrangement of the dimers, $(\mathrm{ZnHTPP})_{2},(\mathrm{ZnOEP})_{2} \mathrm{Ph}$ and various extra-ligands in triads and pentad (HyperChem software package, release 4, semiempirical methods AM1 and PM3). The corresponding extra-ligands were used: (i) porphyrin, $\mathrm{H}_{2} \mathrm{P}$ containing two mesophenyls and two mesopyridyl rings with different positions of both pyridyl rings (opposite and adjacent) and pyridyl nitrogens $\mathrm{N}$ (meta and para): opposite meta-pyridyl rings- $\mathrm{H}_{2} \mathrm{P}(m-\mathrm{Pyr})_{2}$-(iso- $\left.\mathrm{PrPh}\right)_{2}$, adjacent meta-pyridyl rings$\mathrm{H}_{2} \mathrm{P}\left(m^{\wedge} \mathrm{Pyr}\right)_{2}$-(iso- $\left.\mathrm{PrPh}\right)_{2}$ and adjacent para-pyridyl rings- $\mathrm{H}_{2} \mathrm{P}\left(p^{\wedge} \mathrm{Pyr}\right)_{2}(\mathrm{Ph})_{2}$; (ii) porphyrin, $\mathrm{H}_{2} \mathrm{P}$ containing four mesopyridyl rings with meta-nitrogens. For simplicity, mesophenyl rings in $(\mathrm{ZnHTPP})_{2}$ are omitted. 
set-up, described in detail in Ref. [39]. Samples were excited by the pulses of the second harmonic of the YAG: $\mathrm{Nd}^{3+}$ pulse solid laser $\left(\lambda_{\mathrm{ex}}=532 \mathrm{~nm}\right.$, the energy density of $E=0.3-3.0 \mathrm{~mJ} \mathrm{~cm}^{-2}$ with a dispersion of $\pm 5 \%$, the pulse duration $\Delta t_{1 / 2}=15$ ns FWHM). The probing of induced absorption was performed by a filament lamp of KGM type. The recording system based on a diffraction monochromator, detectors (a photomultiplier FEU-84 or germanium photodiode FD-10GA) and a digital oscilloscope S9-8 connected with a personal computer, allowed to register a transient absorption optical density down to $\Delta D \sim 10^{-4}$ with a temporal resolution up to $50 \mathrm{~ns}$ in visibleand near-IR (850-1660 $\mathrm{nm}$ ) region. $\Delta D$ values were obtained for more than 64 laser pulses and then averaged and extrapolated to the maximal pulse intensity, the relative error of $\Delta D$ measurements did not exceed $\pm 5 \%$. In order to diminish the annihilation effects influence on $\mathrm{T}_{1}$-state decays in liquid solutions at $293 \mathrm{~K}$, porphyrin concentrations of $\sim 10^{-6} \mathrm{M}$ were used. For the study of the excited $\mathrm{S}_{1}$ - and $\mathrm{T}_{1}$-states quenching by dissolved molecular oxygen, the measurements were comparatively carried out for degassed and nondegassed samples (purging up to $10^{-5}$ Torr pressure). All photophysical measurements were completed within 1-2 $\mathrm{h}$ following preparation.

The corresponding values of bimolecular rate constants of the excited $\mathrm{S}_{1}{ }^{-}$and $\mathrm{T}_{1}$-states quenching by molecular oxygen were calculated using oxygen solubility in MCH and TOL at 293 $\mathrm{K}[40]$ and the following expression:

$k_{\mathrm{T}, \mathrm{S}}=\frac{\left(\tau_{\mathrm{T}, \mathrm{S}}\right)^{-1}-\left(\tau_{\mathrm{T}, \mathrm{S}}^{0}\right)^{-1}}{\left[\mathrm{O}_{2}\right]}$,

where $\tau_{\mathrm{T}}$ and $\tau_{\mathrm{S}}$ are the corresponding $\mathrm{T}_{1}$ - and $\mathrm{S}_{1}$ states decays of the compounds under consideration in the presence of oxygen, $\tau_{\mathrm{T}}^{0}$ and $\tau_{\mathrm{S}}^{0}$ are decays in degassed solutions, $\left[\mathrm{O}_{2}\right]$ is the concentration of dissolved molecular oxygen at $293 \mathrm{~K}$. As a rule, in calculations of $k_{\mathrm{T}}$ rate constants the value of $\left(\tau_{\mathrm{T}}^{0}\right)^{-1}$ was neglected because of $\tau_{\mathrm{T}}^{0} \gg \tau_{\mathrm{T}}$ (over 23 orders of magnitude [41]). Relative experimental errors in measurements were estimated to be $\pm 3 \%$ for $\tau_{\mathrm{S}}, \pm 5-7 \%$ for $\tau_{\mathrm{T}}$ and $\pm 10-12 \%$ for $k_{\mathrm{S}}$ and $k_{\mathrm{T}}$.

The main procedure for the measurement of the quantum yield of singlet oxygen generation, $\gamma_{\Delta}^{x}$, is based on the comparison of emission intensity of singlet oxygen $\left(\lambda_{\max }=1.27 \mu\right)$ photosensitised by a standard compound (intensity $I_{0}$ ) and by the compound under investigation (intensity $I_{\mathrm{X}}$ ) in the same solvent

$\gamma_{\Delta}^{x}=\gamma_{\Delta}^{0} \frac{I_{x} \times \beta_{0}}{I_{0} \times \beta_{x}}$,

where $\gamma_{\Delta}^{0}$ is the quantum yield of singlet oxygen generation by a standard $\left(\gamma_{\Delta}^{0}=1.0\right.$ for Pd-mesoporphyrin IX and $\gamma_{\Delta}^{0}=0.6$ for chlorophyll " $\mathrm{a}$ " in TOL [41]), $\beta_{0}=\left(1-10^{-D_{0}}\right)$ and $\beta_{x}=\left(1-10^{-D_{x}}\right)$ are fractions of absorbed exciting light by standard and investigated compounds, respectively at given excitation wavelength. $I_{x}$ and $I_{0}$ values were averaged and extrapolated to the maximal pulse intensity after more than 32 laser pulses for every measurement, the relative error of $\gamma_{\Delta}^{x}$ determination did not exceed $\pm 10-15 \%$.

\section{Results and discussion}

\subsection{Steady-state spectral features of the dimers upon interaction with pyridine}

Fig. 4 shows the spectral transformations in absorption and fluorescence spectra observed upon the complexation of the dimers with PYR at $293 \mathrm{~K}$, and Table 1 collects the main spectral-luminescent and photophysical parameters for uncomplexed and complexed species at $77 \mathrm{~K}$.

It should be mentioned that the spectral manifestation and nature of extra-ligation effects for various monomeric $\mathrm{Zn}$-porphyrins have been well documented [12,20,27]. The extra-ligation is due to the interaction of the unshared electron pair of PYR heteroatom $\mathrm{N}$ with empty d-orbitals of porphyrin $\mathrm{Zn}^{2+}$ central ion. The electronic structure of the low-lying $\left(\pi, \pi^{*}\right)$ excited states and intensities of $\mathrm{Q}(0,0)$ electronic transitions upon extra-ligation are described by the Gouterman four-orbital model [42]. Since the highest occupied molecular $\mathrm{a}_{2 \mathrm{u}}$ orbital has electron density at pyrrole nitrogens, Lewis base ligands are expected to increase the energy of this orbital, while the energies of the highest occupied molecular $\mathrm{a}_{1 \mathrm{u}}$ orbital and the lowest unoccupied $e_{\mathrm{g}}$ orbital are not 

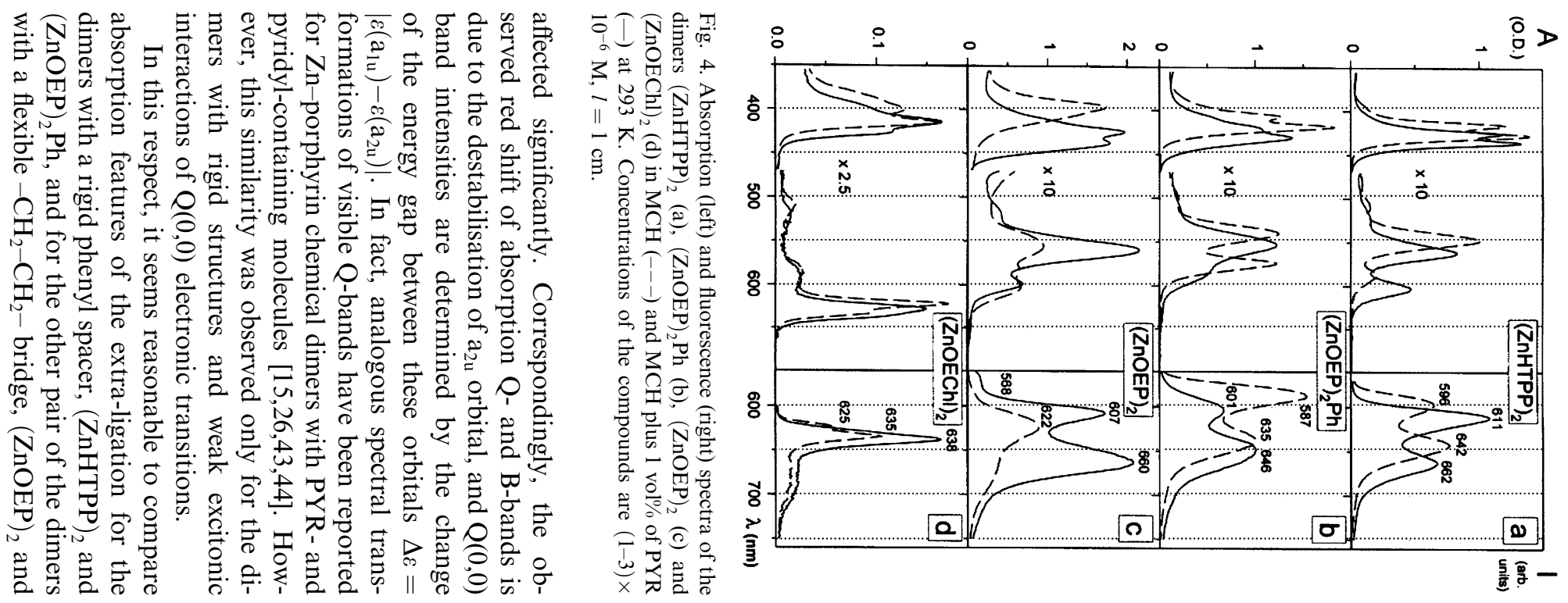

Table 1

Extra-ligation influence on spectral-luminescent and photophysical parameters of $\mathrm{Zn}$-porphyrin and $\mathrm{Zn}$-chlorin chemical dimers at $77 \mathrm{~K}$

\begin{tabular}{|c|c|c|c|c|c|c|c|c|c|}
\hline Compound & Solvent & $\begin{array}{l}\text { Absorption } \\
\lambda_{0-0}(\mathrm{~nm})\end{array}$ & $\begin{array}{l}\text { Fluorescence } \\
\lambda_{0-0}(\mathrm{~nm})\end{array}$ & $\begin{array}{l}\text { Phosphorescence } \\
\lambda_{0-0}(\mathrm{~nm})\end{array}$ & $\begin{array}{l}E\left(\mathrm{~S}_{1}\right)^{\mathrm{a}} \\
\left(\mathrm{cm}^{-1}\right)\end{array}$ & $\begin{array}{l}E\left(T_{1}\right)^{\mathrm{b}} \\
\left(\mathrm{cm}^{-1}\right)\end{array}$ & $\varphi_{\mathrm{F}}$ & $\varphi_{\mathrm{Ph}}$ & $\begin{array}{l}\tau_{\mathrm{Ph}} \\
(\mathrm{ms})\end{array}$ \\
\hline \multirow{2}{*}{$(\mathrm{ZnOEP})_{2} \mathrm{Ph}$} & $\mathrm{MCH}$ & 582 & 589 & 740 & 17079 & 13514 & 0.035 & 0.010 & 38.0 \\
\hline & $\mathrm{MCH}+\mathrm{PYR}$ & 590 & 596 & 748 & 16863 & 13369 & 0.020 & 0.005 & 28.5 \\
\hline \multirow[t]{2}{*}{ Zn-3', $3^{\prime}$-cyclodimer } & $\mathrm{MCH}$ & 593 & 595 & 755 & 16835 & 13245 & 0.015 & 0.015 & 67.0 \\
\hline & $\mathrm{MCH}+\mathrm{PYR}$ & 594 & 596 & 748 & 16807 & 13369 & 0.015 & 0.010 & 38.5 \\
\hline \multirow[t]{2}{*}{$(\mathrm{ZnOEP})_{2}$} & $\mathrm{MCH}$ & 599 & 605 & 764 & 16584 & 13089 & 0.040 & 0.016 & 41.0 \\
\hline & $\mathrm{MCH}+\mathrm{PYR}$ & 595 & 598 & 766 & 16764 & 13055 & 0.035 & 0.006 & 28.0 \\
\hline \multirow{2}{*}{$(\mathrm{ZnHTPP})_{2}$} & $\mathrm{MCH}$ & 615 & 627 & 830 & 16103 & 12048 & 0.035 & 0.001 & 22.0 \\
\hline & $\mathrm{MCH}+\mathrm{PYR}$ & 617 & 633 & 832 & 16000 & 12019 & 0.045 & 0.001 & 16.0 \\
\hline \multirow{2}{*}{$(\mathrm{ZnOEChl})_{2}$} & $\mathrm{MCH}$ & 630 & 631 & 852 & 15873 & 11737 & 0.030 & 0.0002 & 5.0 \\
\hline & $\mathrm{MCH}+\mathrm{PYR}$ & 633 & 634 & 850 & 15798 & 11765 & 0.030 & 0.0002 & 5.0 \\
\hline
\end{tabular}

\footnotetext{
a The energies of the lowest singlet excited states are estimated from absorption and fluorescence spectra of the separate dimers.

${ }^{b}$ The energies of the lowest triplet excited states are estimated from the maximum positions of $\mathrm{Q}(0,0)$ phosphorescence bands. All relative errors of fluorescence and phosphorescence quantum yields $\left(\varphi_{\mathrm{F}}, \varphi_{\mathrm{Ph}}\right)$ and phosphorescence decays $\tau_{\mathrm{Ph}}$ are presented in Section 2.
} 
$(\mathrm{ZnOEChl})_{2}$. The red shift and the inverse character of the redistribution of relative intensities of $\mathrm{Q}(0,0)$ and $\mathrm{Q}(0,1)$ bands for $(\mathrm{ZnHTPP})_{2}$ and $(\mathrm{ZnOEP})_{2} \mathrm{Ph}$ in the presence of PYR (see Fig. 4a and $b$ ) are similar to those known for pyridinated complexes of the corresponding monomers ZnTPP [12] and ZnOEP [20]. In the absence of strong excitonic coupling of $\mathrm{Q}(0,0)$ electronic transitions in these two dimers (molar decimal extinction coefficients are of $\sim 10^{4} \mathrm{M}^{-1} \mathrm{~cm}^{-1}$ [26]), the intensity changes of $\mathrm{Q}(0,0)$ long-wavelength electronic transitions are determined by the destabilisation of highest occupied molecular $\mathrm{a}_{2 \mathrm{u}}$ orbital [42]. In these dimers, the form of Soret bands and corresponding splitting are caused by the excitonic interactions of strong B-transitions [6,16,26] (molar decimal extinction coefficients are of $\sim 3 \times$ $10^{5} \mathrm{M}^{-1} \mathrm{~cm}^{-1}$ [26]). It is seen from Fig. $4 \mathrm{a}$ and $\mathrm{b}$ that in the presence of PYR the splitting of the redshifted Soret bands for (ZnHTPP $)_{2}$ and $(\mathrm{ZnOEP})_{2} \mathrm{Ph}$ is slightly changed with respect to uncomplexed dimers, however the spectral picture of the splitting remains the same practically for both these dimers. This result indicates clearly that for the dimers with a rigid structure the interaction with extra-ligands does not lead to the conformational changes of the complexes.

In contrast, the observed spectral tendencies are not the same for the dimers with a flexible $-\mathrm{CH}_{2}-$ $\mathrm{CH}_{2}-$ spacer (Fig. 4c and d). It is seen from Fig. 4c that for pyridinated complex of the dimer $(\mathrm{ZnOEP})_{2}$ the Soret band exhibits a very large red shift $\left(\sim 1700 \mathrm{~cm}^{-1}\right)$ and a clearly resolved splitting $\left(\Delta v=700 \mathrm{~cm}^{-1}\right)$. In fact, spectral changes in the region of Q-bands may be attributed to the extraligation influence presumably. But the drastic transformations of the Soret band reflect more complex behaviour of the dimer upon interaction with PYR. It is noteworthy that the dimer $(\mathrm{ZnOEP})_{2}$ is characterised by a conformational mobility of porphyrin macrocycles relative to $\mathrm{CH}_{2}-\mathrm{CH}_{2}$ - bond. In this case, using ${ }^{1} \mathrm{H}-\mathrm{NMR}$ data and Draiding structural models we have shown $[45,46]$ that at $293 \mathrm{~K}$ in liquid solutions the dynamic equilibrium is realised between fully staggered and fully eclipsed conformations with variation of the centre-to-centre distance from 10.6 to $5.5 \AA$. As far as the energy of excitonic inter- actions $V_{12}$ depends strongly on the distance $r$ and mutual orientation $f(\theta, \varphi)$ of the interacting dipoles $V_{12} \sim\left(\vec{\mu}_{1} \vec{\mu}_{2} / r^{3}\right) f(\theta, \varphi)[45,47]$ one may conclude that the observed splitting of the Soret band for uncomplexed $(\mathrm{ZnOEP})_{2}$ is attributed to the contribution of both conformations. Correspondingly, upon extra-ligation the dynamic equilibrium shifts to the fully staggered conformation, thus leading to significant changes in Soret region. This conclusion is in a good agreement with theoretical predictions of extra-ligation effects in $(\mathrm{ZnOEP})_{2}$ based on quantum-chemical calculations and point dipole-dipole approximation [45].

In the case of $(\mathrm{ZnOEChl})_{2}$ dimer with the same $-\mathrm{CH}_{2}-\mathrm{CH}_{2}-$ spacer, the existence of hydrogenated pyrrole rings of both halves in the vicinity of $\mathrm{CH}_{2}-\mathrm{CH}_{2}-$ spacer (see Fig. 1) constrains the possibility of the transition from fully staggered to fully eclipsed conformations. Because of these steric limitations in the later dimer the optimal intermediate conformation is realised that is slightly affected by complexation with PYR (Fig. $4 d)$. In addition, as far as strong electronic transitions form both B- and Q-bands in $\mathrm{Zn}$-chlorins, the excitonic splittings are observed in both Soret and visible absorption bands of this dimer. For the rigid dimer $\mathrm{Zn}-3^{\prime}, 3^{\prime}$-cyclodimer with almost orthogonal porphyrin macrocycles $[33,34]$, the PYR action is individual for every half and does not differ from the monomeric case.

At $77 \mathrm{~K}$ absorption and fluorescence spectra of the most uncomplexed dimers are red shifted (compare Fig. 4 and Table 1). In the only one case for the uncomplexed dimer $(\mathrm{ZnOEP})_{2}$ with a flexible ethane bridge, $\mathrm{Q}(0,0)$ absorption bands are blue shifted at $77 \mathrm{~K}$. The reason of that is explained by the shift of the equilibrium to the preferable fully staggered conformation at low temperature [46]. Finally, at $77 \mathrm{~K}$ in most cases the formation of pyridinated complexes manifests itself in the red shift of $\mathrm{Q}(0,0)$ electronic absorption, fluorescence and phosphorescence bands.

\subsection{Photophysical parameters of the dimers upon interaction with pyridine}

Prior analysing the extra-ligation influence on photophysical parameters of $\mathrm{Zn}$-porphyrin or 
$\mathrm{Zn}$-chlorin dimers one should take into account the possible influence of interchromophoric interactions in the dimers on the deactivation of their excited $\mathrm{S}_{1}$ - and $\mathrm{T}_{1}$-states. The comparison of data collected in Tables 1 and 2 (column with fluorescence decays $\tau_{\mathrm{S}}$ at $293 \mathrm{~K}$ for the dimers), and experimental measurements of the fluorescence parameters $\left(\varphi_{\mathrm{F}}, \tau_{\mathrm{S}}\right)$ and the intersystem crossing $S_{1} \leadsto T_{1}$ quantum yields $(\gamma)$ obtained for the corresponding monomers earlier $[34,35,48]$ lead to the following conclusions. For all dimers under consideration two non-radiative channels, $\mathrm{S}_{1} \leadsto \mathrm{T}_{1}$ and $\mathrm{S}_{1} \leadsto \mathrm{S}_{0}$, are hardly dependent on the intermolecular interactions in a temperature range of 77-293 K. Additionally, phosphorescence measurements at $77 \mathrm{~K}$ show that in all dimers rate constants of the non-radiative deactivation $T_{1} \leadsto S_{0}$ are higher by $\sim 2-3$ orders of magnitude with respect to those of the radiative transition $\mathrm{T}_{1} \rightarrow \mathrm{S}_{0}$. Therefore possible deviations of rate constants of the spin-forbidden radiative transition $\mathrm{T}_{1} \rightarrow \mathrm{S}_{0}$ caused by interchromophoric interactions in the dimers may lead to more pronounced changes of $\varphi_{\mathrm{Ph}}$ values while phosphorescence decay values $\tau_{\mathrm{Ph}}$ may remain constant practically or change in a less extent.

Thus, keeping in mind these facts one may compare the deactivation processes of singlet and triplet states for uncomplexed dimers and their complexes with PYR. From the data summarised in Tables 1 and 2 it is seen that coordination of
PYR to the zinc-dimers moiety has not a substantial effect on both fluorescence quantum yields and lifetimes (a mean relative decrease of experimental values is less than $\sim 8 \%$ ). It means that additional non-radiative deactivation processes of $\mathrm{S}_{1}$-states are not enhanced in pyridinated dimers in a temperature range of 293-77 K.

In contrast, data of Table 1 evidently show that the parameters of the dimer triplet states are more sensitive to the coordination with PYR. There are some noticeable features of this effect: (1) Phosphorescence lifetimes and quantum yields exhibit a decrease by $1.5-2.5$ times with respect to those for uncomplexed species. (2) The additional $\mathrm{T}_{1}$-state quenching in pyridinated complexes diminishes upon the triplet level lowering for a set of the investigated compounds, $(\mathrm{ZnOEP})_{2} \mathrm{Ph} \rightarrow \mathrm{Zn}-3^{\prime}, 3^{\prime}-$ cyclodimer $\rightarrow(\mathrm{ZnOEP})_{2} \rightarrow(\mathrm{ZnHTPP})_{2} \rightarrow(\mathrm{ZnO}$ $\mathrm{EChl})_{2}$ (the corresponding $\mathrm{T}_{1}$-state energies are presented in Table 1).

In fact, there are some means by which $\pi$-conjugated macrocycles in the dimers may enhance $\mathrm{T}_{1} \leadsto \mathrm{S}_{0}$ non-radiative decay. For typical large aromatic molecules with the ground and excited $\left(\pi, \pi^{*}\right)$ electronic states having a single accessible conformation, $\mathrm{T}_{1} \rightsquigarrow \mathrm{S}_{0}$ non-radiative intersystem crossing follows the well-known energy gap low for radiationless decay $[49,50]$

$$
K_{\mathrm{q}}=K_{\mathrm{T}_{1} \mathrm{~s}_{0}}=A\left\langle\chi_{\mathrm{i}} \mid \chi_{\mathrm{f}}\right\rangle=A \exp \left(-\alpha \Delta E_{\mathrm{T}_{1} \mathrm{~s}_{0}}\right),
$$

Table 2

Singlet and triplet lifetimes and bimolecular rate constants of excited states (quenching by molecular oxygen for dimers in TOL and TOL + PYR at $293 \mathrm{~K}$ )

\begin{tabular}{llllll}
\hline Compound & Solvent & $\tau_{\mathrm{S}}(\mathrm{ns})$ & $\tau_{\mathrm{T}}(\mathrm{ns})$ & $k_{\mathrm{T}} \times 10^{9}\left(\mathrm{M}^{-1} \mathrm{~s}^{-1}\right)$ & $k_{\mathrm{T}}(\mathrm{lig}) / k_{\mathrm{T}}^{\mathrm{a}}$ \\
\hline$(\mathrm{ZnOEP})_{2} \mathrm{Ph}$ & TOL & 1.2 & 495 & 1.1 & 1.0 \\
& TOL + PYR & 1.15 & 490 & 1.1 & 1.2 \\
$\mathrm{Zn}-3^{\prime}, 3^{\prime}$-cyclodimer & TOL & 2.5 & 355 & 1.6 & 1.6 \\
& TOL + PYR & 2.5 & 295 & 1.9 & 1.2 \\
$(\mathrm{ZnOEP})_{2}$ & TOL & 1.3 & 440 & 1.9 & 1.10 \\
$(\mathrm{ZnHTPP})_{2}$ & TOL + PYR & 1.2 & 205 & 0.95 & 1.05 \\
$(\mathrm{ZnOEChl})_{2}$ & TOL & 1.5 & 590 & 1.6 & 1.25 \\
& TOL + PYR & 1.4 & 500 & 2.0 & \\
\hline
\end{tabular}

\footnotetext{
Meanings of all indexes are cited in the text. Relative experimental errors in measurements were estimated to be $\pm 3 \%$ for $\tau_{\mathrm{S}}, \pm 5-7 \%$ for $\tau_{\mathrm{T}}$ and $\pm 10-12 \%$ for $k_{\mathrm{T}}$.

${ }^{\mathrm{a}} k_{\mathrm{T}}\left(\right.$ lig) are rate constants of triplet state quenching for extra-ligated dimers in TOL + PYR solution. Measurements of $\tau_{\mathrm{S}}$ and $\tau_{\mathrm{T}}$ decays were carried out in solutions at normal atmospheric pressure.
} 
where the rate is determined in part by the vibrational-wave function overlap (Frank-Condon) factor $f_{\mathrm{v}}=\left\langle\chi_{\mathrm{i}} \mid \chi_{\mathrm{f}}\right\rangle$ and decreases exponentially with increasing $\mathrm{T}_{1}-\mathrm{S}_{0}$ energy gap, $\Delta E_{\mathrm{T}_{1} \mathrm{~S}_{0}}$. For uncomplexed dimers for which phosphorescence decays are shortened from $67 \mathrm{~ms}$ down to $5 \mathrm{~ms}$ upon the triplet state energy lowering by $\sim 1800$ $\mathrm{cm}^{-1}$, the experimental plot of $\ln \left(1 / \tau_{\mathrm{Ph}}\right)$ versus $E\left(\mathrm{~T}_{1}\right)$ is in a reasonable agreement with theoretical predictions (Fig. 5, dependence 1). Some deviations from a linearity may be explained by various electron donor-acceptor nature of side substituents and spacers that is not included in the theory. It is seen from Table 1 that coordination of the central $\mathrm{Zn}$ ion with PYR leads, as a rule, to the decrease of the $T_{1}$-state energy in the dimers. Correspondingly, it results in shortening of $\tau_{\mathrm{Ph}}$ values caused by the increase of Frank-Condon factor for the non-radiative transitions $T_{1} \leadsto S_{0}$. In fact, this tendency manifests itself satisfactorily in the experimental dependency $\ln \left(1 / \tau_{\mathrm{Ph}}\right) \sim E\left(\mathrm{~T}_{1}\right)$ for the pyridinated dimers (Fig. 5, dependence 2 ). In the last case, although these simple FrankCondon arguments provide a general way of rationalising the enhanced non-radiative intersystem $\mathrm{T}_{1} \rightsquigarrow \mathrm{S}_{0}$ crossing, the real situation seems to be more complex.

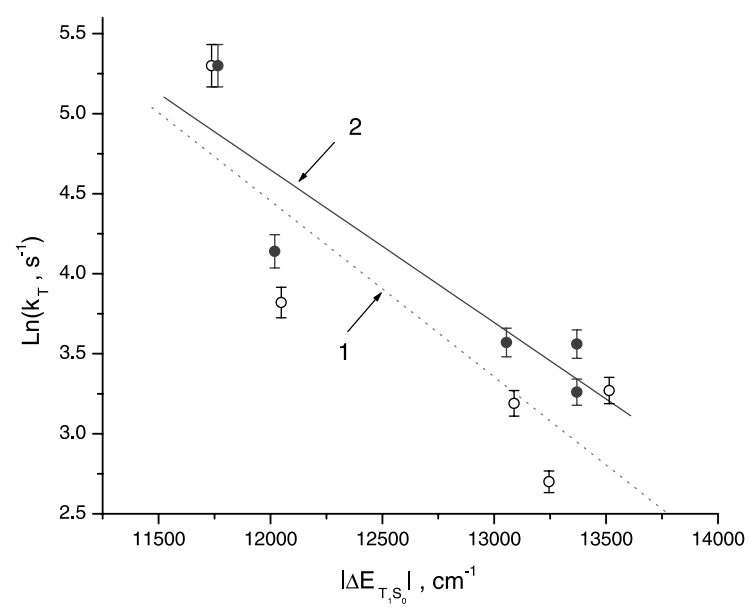

Fig. 5. Energy gap relations for uncomplexed $(1, \boldsymbol{\bullet})$ and complexed $(2, \bigcirc)$ dimers. Experimental points were leastsquare fitted by a linear function $y=a+b x$ with $a=17.66$, $b=-10.0$ for Eq. (1) and $a=16.10, b=-9.54$ for Eq. (2).
Firstly, in monomeric Zn-porphyrins [51,52] the extra-ligand vibrations as accepting modes take part in the additional non-radiative deactivation of the excited $\mathrm{T}_{1}$-state [51,52]. Correspondingly, this quenching effect seems to be operative in the dimers under study. Secondly, the extra-ligation causes the weakening of central metal-pyrrole nitrogens interactions, thus leading to the lowering the energy of singlet $\sigma, \pi^{*}$ states [53]. It results in a strengthening of the spin-orbit coupling, and the non-radiative triplet decay rate becomes larger. Thirdly, like in sterically hindered porphyrins [54], the out-of-plane distortion of the porphyrin macrocycle upon extra-ligation may facilitate the spin-orbit coupling due to the overlap of the central nitrogen n-orbitals and porphyrin $\pi$-orbitals, thus resulting in a strengthening of the non-radiative transition $T_{1} \leadsto S_{0}$ rate constants. Eventually all the above mentioned reasons complement each other in the enhancement of $T_{1}$-state non-radiative decay in the dimers coordinated with PYR. Finally, the conclusion that comes from Table 1 and Fig. 5, is as follows.

The dimers $(\mathrm{ZnOEP})_{2} \mathrm{Ph}, \mathrm{Zn}-3^{\prime}, 3^{\prime}$-cyclodimer and $(\mathrm{ZnOEP})_{2}$ with high-energy triplet states and relatively long phosphorescence decays $\tau_{\mathrm{Ph}}$ are sensitive to the coordination with pyridine leading to enhancing non-radiative deactivation of $T_{1}$ states. However, for the dimers (ZnHTPP) $)_{2}$ and $(\mathrm{ZnOEChl})_{2}$ with low-energy triplet states and relatively short lifetimes $\tau_{\mathrm{Ph}}$ the rate constants of intrinsic non-radiative deactivation processes $\mathrm{T}_{1} \leadsto \mathrm{S}_{0}$ (due to Frank-Condon factor presumably) are so large that additional channels of the non-radiative deactivation of $\mathrm{T}_{1}$-states caused by the extra-ligation seem in comparison not very effective.

\subsection{Interaction of the dimers with molecular oxygen in liquid solutions at $293 \mathrm{~K}$}

Generally, Zn-porphyrins and Zn-chlorins are characterised by relatively short fluorescence lifetimes in degassed solutions $\left(\tau_{\mathrm{S}}^{0}=1.2-1.6 \mathrm{~ns}\right.$ for monomers [20,35,45] and some chemical dimers $[55,56])$, and, correspondingly, are hardly influenced by the presence of oxygen in liquid solutions at normal atmospheric pressure at $293 \mathrm{~K}[55,56]$. 
Table 2 collects experimental $\tau_{\mathrm{T}}$ values and corresponding bimolecular rate constants $k_{\mathrm{T}}$ showing the specificity of the dimer $\mathrm{T}_{1}$-states quenching by molecular oxygen.

According to Ref. [57] the process of $T_{1}$-states quenching by $\mathrm{O}_{2}$ is realised via non-radiative transitions between electronic states in an intermediate short living weak collision complex formed as a result of a diffusional contact of a given excited organic molecule -with an oxygen molecule (Fig. 6). From this point of view, the quenching of $\mathrm{T}_{1}$-state of the organic molecule $\left({ }^{3} \mathrm{M}_{1}\right)$ may take place via different ways depending on the spin state of the collision complex:

$$
\begin{gathered}
{ }^{3} \mathrm{M}_{1}+{ }^{3} \mathrm{O}_{2} \underset{k_{\text {dis }}}{\stackrel{\mathrm{g}_{1}}{k_{\text {diff }}}}\left[{ }^{3} \mathrm{M}_{1} \cdots{ }^{3} \mathrm{O}_{2}\right] \stackrel{k_{\Delta}}{\rightsquigarrow} \\
{\left[{ }^{1} \mathrm{M}_{0} \cdots{ }^{1} \mathrm{O}_{2}\left({ }^{1} \Delta_{\mathrm{g}}\right)\right] \stackrel{k_{\text {dis }}}{\longrightarrow} \mathrm{M}_{0}+{ }^{1} \Delta_{\mathrm{g}}} \\
{ }^{3} \mathrm{M}_{1}+{ }^{3} \mathrm{O}_{2} \underset{\mathrm{g}_{3} k_{\text {diff }}}{\stackrel{k_{\text {dis }}}{g^{2}}}\left[{ }^{3} \mathrm{M}_{1} \cdots{ }^{3} \mathrm{O}_{2}\right] \stackrel{k_{\mathrm{TS}}}{\leadsto} \\
{ }^{3}\left[{ }^{1} \mathrm{M}_{0} \cdots{ }^{3} \mathrm{O}_{2}\right] \stackrel{k_{\text {dis }} 1}{\longrightarrow} \mathrm{M}_{0}+{ }^{3} \mathrm{O}_{2}
\end{gathered}
$$

Here, $k_{\text {diff }}$ is a diffusion rate constant; rate constants $k_{\Delta}$ and $k_{\mathrm{ST}}$ are shown and determined in Fig. $6 ; g_{1}=1 / 9$ and $g_{3}=1 / 3$ are spin-statistical factors reflecting the rate constants of the formation of the complex states ${ }^{1}\left[{ }^{3} \mathrm{M}_{1} \cdots{ }^{3} \mathrm{O}_{2}\right]$ and ${ }^{3}\left[{ }^{3} \mathrm{M}_{1} \ldots{ }^{3} \mathrm{O}_{2}\right]$, correspondingly; $k_{\mathrm{dis}}$ is the rate constant of the complex dissociation. In the case of porphyrins and chlorins, the relation $k_{\mathrm{dis}} \approx k_{\mathrm{S}}$ is used (where $k_{\mathrm{S}}$ is the bimolecular rate constant of $\mathrm{S}_{1}$-state quenching by $\mathrm{O}_{2}$ ) [41]. As it was discussed in Ref. [41,57], at the same quenching mechanism (exchange and donor-acceptor interactions) the quenching scheme may differ. Scheme I with generation of singlet oxygen corresponds to $k_{\mathrm{T}}=\frac{1}{9} k_{\mathrm{S}}$, while Scheme II without singlet oxygen generation is operative at $k_{\mathrm{T}}=\frac{1}{3} k_{\mathrm{S}}$.

There are some features of $\mathrm{T}_{1}$-states quenching by $\mathrm{O}_{2}$ for uncomplexed dimers at $293 \mathrm{~K}$. All dimers exhibit a noticeable decrease (by $15-30 \%$ ) of bimolecular rate constants $k_{\mathrm{T}}$ (Table 2) in comparison with those known for the corresponding precursor monomers with the same side substituents $[20,54]$. The reason of that may be explained by the exchange $\mathrm{T}-\mathrm{T}$ energy transfer realising in $\mathrm{Zn}$-porphyrin chemical dimers with phenyl spacer at distances $R_{\mathrm{DA}}=12.6-17.0 \AA$ with rate constants of $k_{\mathrm{ET}} \approx 10^{5}-10^{6} \mathrm{~s}^{-1}[58,59]$. If one takes into account $k_{\mathrm{T}}$ values for monomeric species $\left(k_{\mathrm{T}}=(1.5-2) \times 10^{9} \mathrm{M}^{-1} \mathrm{~s}^{-1}[41,55]\right)$ and the concentration of the dissolved oxygen in TOL $\left(\left[\mathrm{O}_{2}\right]=1.8 \times 10^{-3} \mathrm{M}[40]\right)$ it follows that rate constants of $\mathrm{T}_{1}$-state quenching by $\mathrm{O}_{2}$ for monomers are of $k_{\mathrm{q}}=k_{\mathrm{T}} \times\left[\mathrm{O}_{2}\right] \approx 3 \times 10^{6} \mathrm{~s}^{-1}$. Correspondingly, the competition between the intradimer $\mathrm{T}-\mathrm{T}$ energy transfer and quenching of $\mathrm{T}_{1}$-excited subunit by molecular oxygen results in the relative decrease of the experimental bimolecular rate constants $k_{\mathrm{T}}$ for the dimers with respect to those found for monomeric porphyrins at the same conditions.

It is seen from Table 2 that $k_{\mathrm{T}}$ values for the dimers are sequentially increased in the following set: $(\mathrm{ZnOEP})_{2} \mathrm{Ph}, \quad(\mathrm{ZnHTPP})_{2} \rightarrow(\mathrm{ZnOEP})_{2} \rightarrow$ $\mathrm{Zn}-3^{1}, 3^{\prime}$-cyclodimer, $(\mathrm{ZnOEChl})_{2}$. As it was mentioned above (Schemes I and II) $\mathrm{T}_{1}$-state quenching by $\mathrm{O}_{2}$ is an electron donor-acceptor by nature $\left[\mathrm{M}^{+} \ldots \mathrm{O}_{2}^{-}\right]$and thus correlates with one electron oxidation potentials $E_{1 / 2}^{\mathrm{ox}}$ of porphyrins and chlorins $[41,55,60]$. $\mathrm{Zn}$-porphyrins with mesophenyls are characterized by higher $E_{1 / 2}^{o x}$ values in comparison with $\mathrm{Zn}$-octaethylporphyrins $\left(E_{1 / 2}^{\mathrm{ox}}=0.63\right.$ $\mathrm{V}$ vs. SCE for $\mathrm{ZnOEP}$ [61]). In its turn, $E_{1 / 2}^{\text {ox }}$ potentials in $\mathrm{Zn}$-chlorins $\left(E_{1 / 2}^{\mathrm{ox}}=0.20 \mathrm{~V}\right.$ vs. SCE for ZnOEChl [61]) and Zn-cyclopentaneporphyrins are lower than that for ZnOEP. Therefore the sequential increase of $k_{\mathrm{T}}$ values in the presented set of the dimers reflects qualitatively the corresponding $E_{1 / 2}^{\text {ox }}$ values lowering.

In the case of phenyl bridged $(\mathrm{ZnOEP})_{2} \mathrm{Ph}$ and $(\mathrm{ZnHTPP})_{2}$ dimers, $k_{\mathrm{T}}$ values are scarcely affected by the coordination with PYR (Table 2). One should propose that a small decrease of $E_{1 / 2}^{\mathrm{ox}}$ values for pyridinated $\mathrm{Zn}$-porphyrins (by $0.02-0.11 \mathrm{~V}$ $[15,62])$ is not enough in order to be detected in a measurable increase of $k_{\mathrm{T}}$. For example, such slow dependence of $k_{\mathrm{T}}$ values on the same $E_{1 / 2}^{\mathrm{ox}}$ changes has been experimentally observed for TPP and its halogen substituted analogue [60]. For the dimers $(\mathrm{ZnOEChl})_{2}$ and $\mathrm{Zn}-3^{\prime}, 5^{\prime}$-cyclodimer with essentially lower $E_{1 / 2}^{\text {ox }}$ values the extra-coordination manifests itself in $20-25 \%$ rise of $k_{\mathrm{T}}$ values. It may be explained by larger changes of $E_{1 / 2}^{o x}$ potentials for these pyridinated dimers. 


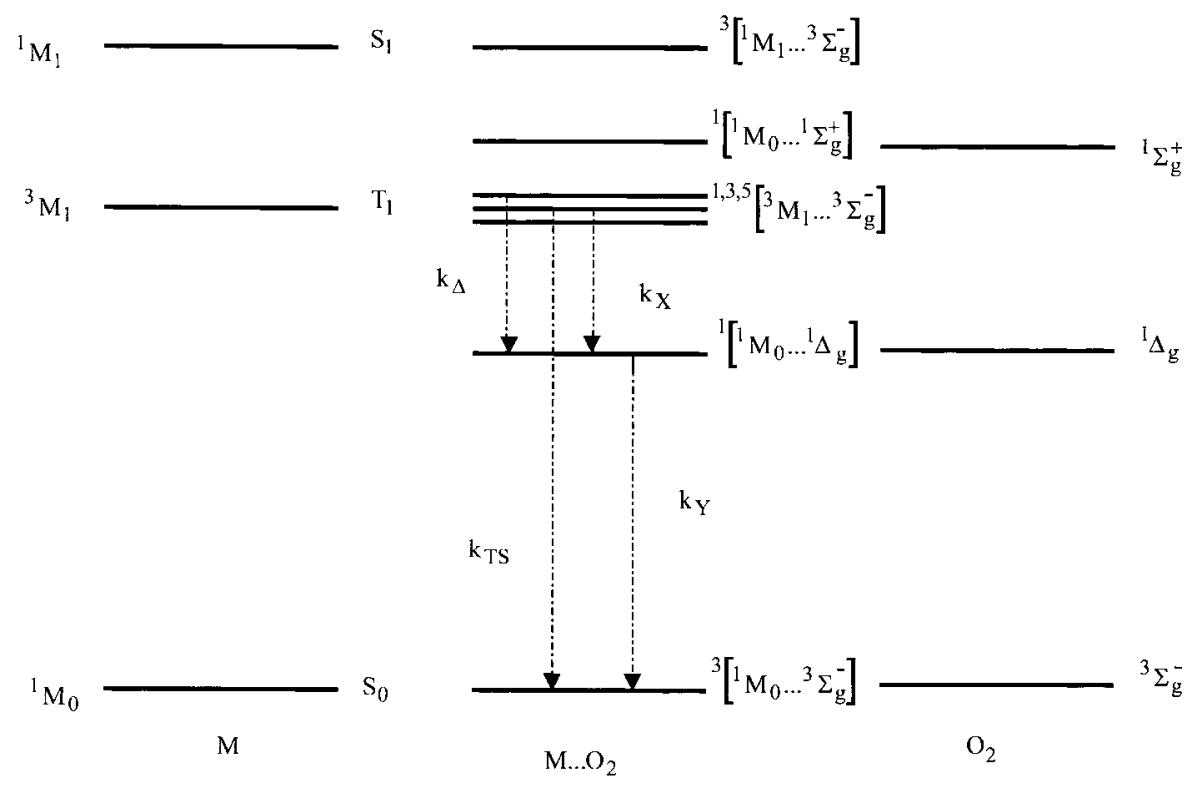

Fig. 6. Schematic diagram [41] of the lowest excited states for organic molecule (M), molecular oxygen $\left(\mathrm{O}_{2}\right)$ and corresponding collision complex $\left(\mathrm{M} \cdots \mathrm{O}_{2}\right)$ in arbitrary scale. Charge transfer state is not shown. Indicated are rate constants of the following pathways in collision complex: $k_{\mathrm{TS}}$, non-radiative intersystem crossing; $k_{\Delta}$, singlet oxygen generation; $k_{\mathrm{X}}$, non-radiative conversion; $k_{\mathrm{Y}}$, internal conversion.

Finally, the most pronounced oxygen-induced $\mathrm{T}_{1}$-state quenching (by $60 \%$, Table 2 ) is found for pyridinated dimer $(\mathrm{ZnOEP})_{2}$ with a flexible $-\mathrm{CH}_{2}-$ $\mathrm{CH}_{2}$ - bridge. There are two factors that come into play here. Firstly, electron-donating ethane bridge in the dimer may strengthen the PYR action in oxygen-induced $\mathrm{T}_{1}$-state quenching (effect of $E_{1 / 2}^{\mathrm{ox}}$ decrease). Secondly, as noted above, PYR-coordinated $(\mathrm{ZnOEP})_{2}$ is in the opened fully staggered conformation. It means practically that the crosssection of the dimer-oxygen interaction becomes larger thus leading to the increase of the experimentally detected quenching. It is not excluded that the last conformational effect may be operative partly in $(\mathrm{ZnOEChl})_{2}$ dimer being restricted due to the steric interactions of neighbouring hydrated pyrrole rings belonging to different halves.

\subsection{Dynamics of relaxation processes in self- assembled porphyrin triads at $293 \mathrm{~K}$}

Fig. 7 illustrates absorption and fluorescence spectra of the triad $(\mathrm{ZnOEP})_{2} \mathrm{Ph} \otimes \mathrm{H}_{2} \mathrm{P}-\left(m^{\wedge} \mathrm{Pyr}\right)_{2}-$ (iso- $\mathrm{PrPh})_{2}$ at room temperature. In fact, changes of the visible $\mathrm{Q}(0,0)$ and $\mathrm{Q}(0,1)$ absorption bands of the dimers in triads obtained at molar ratios $C_{\text {ligand }} / C_{\text {dimer }} \approx 1.0 / 1.1$ reflect the same tendencies as observed for their pyridinates (compare Figs. $4 \mathrm{~b}$ and 7). The triads exhibit absorption spectra that are almost a composite of the spectra of the interacting porphyrin extra-ligand and the dimer. The same spectral features in absorption are typical for pentads formed by the complexation of tetrapyridyl substituted porphyrin extra-ligands with two $\mathrm{Zn}$-porphyrin dimers in solutions at molar ratios $C_{\text {ligand }} / C_{\text {dimer }} \approx 1.1 / 2.0$ [6]. Nevertheless, two principle differences are characteristic for the triads and pentads with respect to the pyridinated dimers: (1) Because of the co-operative twofold extra-ligation, complexation constants upon triad formation $\left(K_{\mathrm{C}} \sim 10^{6}-10^{7} \mathrm{M}^{-1}\right)$ are by about two orders of magnitude higher as compared to pyridinated dimers. (2) The fluorescence of the dimers $(\mathrm{ZnOEP})_{2} \mathrm{Ph}$ or $(\mathrm{ZnHTPP})_{2}$ within the triads and pentads are strongly quenched while the extra-ligand emission is easily detected (Fig. 7) 


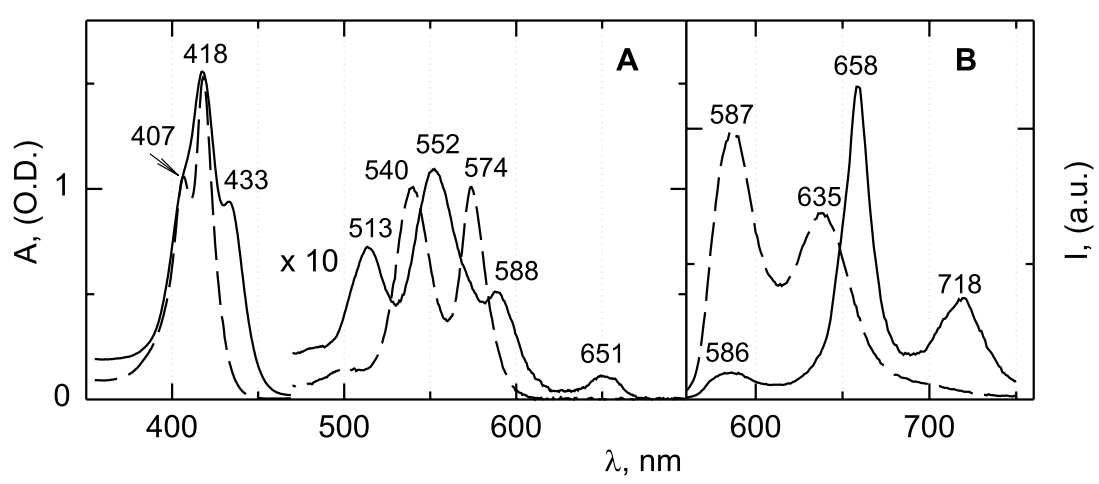

Fig. 7. Absorption (A) and fluorescence spectra (B, $\lambda_{\mathrm{ex}}=545 \mathrm{~nm}$ is an isosbestic point) of the dimer $(\mathrm{ZnOEP})_{2} \mathrm{Ph}(---)$ and the triad $(\mathrm{ZnOEP})_{2} \mathrm{Ph} \otimes \mathrm{H}_{2} \mathrm{P}-\left(m^{\wedge} \mathrm{Pyr}\right)_{2}$-(iso- $\left.\mathrm{PrPh}\right)_{2}(-)$ at molar ratio $C_{\text {ligand }} / C_{\text {dimer }}=1.05$ in $\mathrm{MCH}$ at $293 \mathrm{~K}$. The low intense unshifted fluorescence band at $\lambda_{\max }=586 \mathrm{~nm}$ in triad solution belongs to the remaining uncoupled dimer.

[6,26]. In this respect, some experimental verifications are of interest: (1) What subunit of the arrays is responsible for the interaction with molecular oxygen in liquid solutions? (2) Does this interaction differ from that for monomers and does it vary for the triads and pentads of different but controlled geometry?

Before we do so we would like to point out, that in the systems under consideration the dynamics of excitation energy relaxation processes is rather complex depending on the spectral-kinetic and redox properties of the interacting subunits as well as on temperature and the solvent polarity [30]. The main pathways and mechanisms of the primary photoinduced processes in triads based on the dimer $(\mathrm{ZnOEP})_{2} \mathrm{Ph}$ and various porphyrin and chlorin extra-ligands were evaluated using steadystate measurements, time correlated single photon counting technique and femtosecond pump-probe spectroscopy, and are properly described in our forthcoming paper [63] including theoretical analysis in the frame of the reduced density matrix formalism. Based on this results, here we define the sequence of photophysical events leading to the formation of the final excited states of the triad subunit that may interact with molecular oxygen (Fig. 8).

The excitation of the triad $(\mathrm{ZnOEP})_{2} \mathrm{Ph} \otimes \mathrm{H}_{2} \mathrm{P}$ $\left(m^{\wedge} \mathrm{Pyr}\right)_{2}$-(iso-PrPh $)_{2}$ at $555 \mathrm{~nm}$ in TOL at $293 \mathrm{~K}$ leads to the formation of the locally excited singlet state of the dimer $\left({ }^{1}\right.$ Dimer $\left.^{*} \cdots \mathrm{H}_{2} \mathrm{P}\right)$. A strong fluorescence quenching of the dimer is observed in this case. The non-radiative relaxation of the dimer $\mathrm{S}_{1}$-state in the triads takes place within $1.6 \mathrm{ps}$ with respect to $\tau_{\mathrm{S}}=1,2 \mathrm{~ns}$ for individual dimer (see Table 2). Intrinsic radiative (fluorescence) and non-radiative decay of the dimer $(\mathrm{ZnOEP})_{2} \mathrm{Ph}$ (rate constant $k_{1}=1 / \tau_{\mathrm{S}}=1 / 1.2 \quad \mathrm{~ns}=8.3 \times$ $10^{8} \mathrm{~s}^{-1}$ ) is essentially slower and does not compete with additional non-radiative channels of the dimer $\mathrm{S}_{1}$-state decay in the triad. Namely this reason leads to the conclusion that the direct population of the dimer $T_{1}$-state via intersystem crossing $S_{1}\left({ }^{1}\right.$ Dimer $\left.^{*}\right) \leadsto \mathrm{T}_{1}\left({ }^{3}\right.$ Dimer $\left.^{*}\right)$ with a rate constant of $k_{\mathrm{ISC}} \sim(5-7) \times 10^{7} \mathrm{~s}^{-1}$ (for $\mathrm{Zn}$-porphyrin dimers $[35,46])$ is probably slow in the triad also.The observed fluorescence quenching of the dimer is followed by the population of the locally excited singlet state of the extra-ligand (Dimer $\cdots{ }^{1} \mathrm{H}_{2} \mathrm{P}^{*}$ ) via energy transfer and the formation of the radical ion pair singlet state ${ }^{1}\left(\right.$ Dimer $\left.^{+} \cdots \mathrm{H}_{2} \mathrm{P}^{-}\right)$. This indicates that both singlet-singlet energy transfer $(\mathrm{ZnOEP})_{2} \mathrm{Ph} \rightarrow \mathrm{H}_{2} \mathrm{P}$ (rate constant $k_{5}$ ) and photoinduced electron transfer from the dimer to the extra-ligand (rate constant $k_{6}$ ) are responsible for the fast non-radiative deactivation of the dimer $\mathrm{S}_{1}$-state, $\left(k_{5}+k_{6}\right)=1 / 1.6 \mathrm{ps}=6.25 \times 10^{11} \mathrm{~s}^{-1}$. This means that neither $S_{1}$-state (strongly quenched) nor $T_{1}$ state (not populated) of the dimer in triads and pentads can be operative upon interaction with molecular oxygen.

The dynamics of the locally excited singlet state of the extra-ligand (Dimer ${ }^{1}{ }^{1} \mathrm{H}_{2} \mathrm{P}^{*}$ ) in triads of 


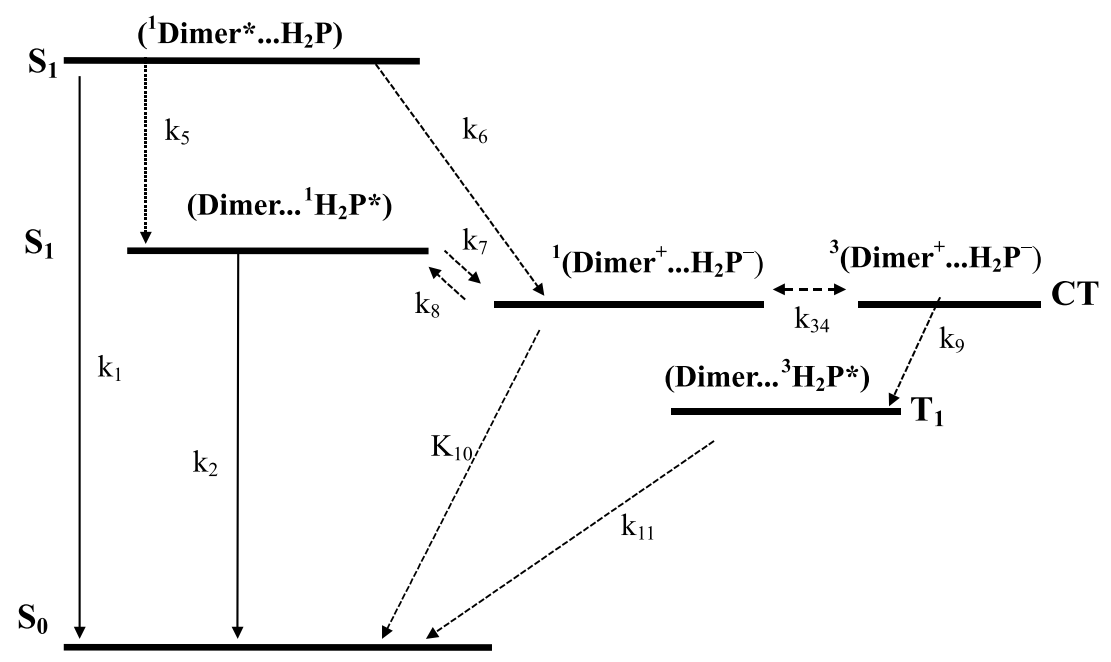

Fig. 8. Schematic energy level diagram for low-lying locally excited singlet states of the dimer $(\mathrm{ZnOEP})_{2} \mathrm{Ph}\left\{\mathrm{S}_{1}\left(\mathrm{Dimer}^{*} \cdots \mathrm{H}_{2} \mathrm{P}\right)\right\}$, the extra-ligand $\mathrm{H}_{2} \mathrm{P}\left\{\mathrm{S}_{1}\right.$ (Dimer $\left.\left.\cdots{ }^{1} \mathrm{H}_{2} \mathrm{P}^{*}\right)\right\}$, locally excited triplet state of $\mathrm{H}_{2} \mathrm{P}\left\{\mathrm{T}_{1}\right.$ (Dimer $\left.\left.\cdots{ }^{3} \mathrm{H}_{2} \mathrm{P}^{*}\right)\right\}$, radical ion pair singlet $\left\{\mathrm{CT}{ }^{1}\left(\right.\right.$ Dimer $\left.\left.^{+} \ldots \mathrm{H}_{2} \mathrm{P}^{-}\right)\right\}$and triplet $\left\{\mathrm{CT}^{3}\left(\right.\right.$ Dimer $\left.\left.^{+} \ldots \mathrm{H}_{2} \mathrm{P}^{-}\right)\right\}$states. Triplet state of the dimer is not populated in triads and pentads and thus not shown. Indicated are rate constants of the following pathways: $k_{1}$, fluorescence and non-radiative decay of the dimer $(\mathrm{ZnOEP})_{2} \mathrm{Ph} ; k_{2}$, fluorescence and non-radiative decay of the extra-ligand $\mathrm{H}_{2} \mathrm{P}$ (intersystem crossing $\mathrm{S}_{1} \leadsto \mathrm{T}_{1}$ in the extra-ligand is not shown); $k_{5}$, singlet-singlet energy transfer from the dimer to the extra-ligand $(\mathrm{ZnOEP})_{2} \mathrm{Ph} \rightarrow \mathrm{H}_{2} \mathrm{P} ; k_{6}$, photoinduced electron transfer from the dimer to the extra-ligand leading to the singlet radical ion pair state formation; $k_{7}$, photoinduced hole transfer from the extraligand to the dimer leading to the singlet radical ion pair state formation; $k_{8}$, thermally activated charge recombination from the singlet radical ion pair state to the extra-ligand locally excited singlet state; $k_{34}$, spin rephasing between the singlet and triplet radical ion pairs; $k_{9}$, charge recombination from the triplet state of the radical ion pair to the locally excited triplet state of the extra-ligand; $k_{10}$, charge recombination from the singlet state of the radical ion pair to the ground state; $k_{11}$, non-radiative intersystem crossing $\mathrm{T}_{1} \leadsto \mathrm{S}_{0}$ from the extra-ligand locally excited state to the ground state.

various structure is also governed by several processes. It may be populated by direct excitation from the ground state or via S-S energy transfer from the dimer. In its turn, the extra-ligand $\mathrm{S}_{1}$ state decay is caused by the interplay of two processes: (i) the photoinduced hole transfer from the excited state of the extra-ligand (Dimer $\cdots{ }^{1} \mathrm{H}_{2} \mathrm{P}^{*}$ ) to the dimer leading to the singlet radical ion pair state formation ${ }^{1}\left(\right.$ Dimer $\left.^{+} \cdots \mathrm{H}_{2} \mathrm{P}^{-}\right)$, with a rate constant of $k_{7}=1 / 1.6 \mathrm{ps}=6.25 \times 10^{11} \mathrm{~s}^{-1}$, and (ii) the effective thermally activated charge recombination from the singlet radical ion pair state ${ }^{1}\left(\right.$ Dimer $\left.^{+} \cdots \mathrm{H}_{2} \mathrm{P}^{-}\right)$to the extra-ligand $\mathrm{S}_{1}$-state (Dimer $\cdots{ }^{1} \mathrm{H}_{2} \mathrm{P}^{*}$ ) with a rate constant of $k_{8} \approx 10^{11}$ $\mathrm{s}^{-1}$. Such complex $\mathrm{S}_{1}$-state dynamics manifests itself in a noticeable $\tau_{\mathrm{S}}$ shortening and a decrease of the fluorescence quantum yield $\varphi_{\mathrm{F}}$ for extra-ligands in triads and pentads with respect to those for uncomplexed pyridyl substituted porphyrins in degassed solutions at $293 \mathrm{~K}$ (Table 3). It is also not excluded that the $\tau_{\mathrm{S}}$ shortening for these extra-ligands in the triads may be enhanced by mixing of a close-lying CT-state with a locally excited $S_{1}$ state thus leading to the rise of non-radiative transitions between $\mathrm{S}_{1}$ - and $\mathrm{S}_{0}$-states in the ligand [64]. All these charge transfer and recombination processes are essentially faster than intersystem crossing $S_{1} \rightsquigarrow T_{1}$ in porphyrin extra-ligand $\left(k_{\mathrm{ISC}} \sim(5-7) \times 10^{7} \mathrm{~s}^{-1}\right.$ for porphyrin free bases $[34,41,60])$. Thus, the extra-ligand $T_{1}$-state in triads and pentads cannot be populated via simple $\mathrm{S}_{1} \leadsto \mathrm{T}_{1}$ process.

Nevertheless, Fig. 9 clearly shows that the transient absorption spectrum of the triad $(\mathrm{ZnOEP})_{2} \mathrm{Ph} \otimes \mathrm{H}_{2} \mathrm{P}-\left(m^{\wedge} \mathrm{Pyr}\right)_{2}$-(iso- $\left.\mathrm{PrPh}\right)_{2}$ at $4.5 \mathrm{~ns}$ delay time differs principally from that detected at ps delay times. The bleaching bands of this spectrum are almost, "free-base like" while at the short time delays they resemble more "triad-like" i.e. a superposition of the $\mathrm{H}_{2} \mathrm{P}$ and $(\mathrm{ZnOEP})_{2} \mathrm{Ph}$ 
absorption bands. The spectrum at late times corresponds better to known transient $\mathrm{T}-\mathrm{T}$ spectra for porphyrin free bases measured at ms time scales $[65,66]$. On the base of all these facts it is reasonable to assume that the population of the locally excited $\mathrm{T}_{1}$-state of porphyrin extra-ligands (Dimer $\cdots{ }^{3} \mathrm{H}_{2} \mathrm{P}^{*}$ ) in triads and pentads takes place from the upper-lying triplet radical ion pair state ${ }^{3}\left(\right.$ Dimer $\left.^{+} \cdots \mathrm{H}_{2} \mathrm{P}^{-}\right)$with the rate constant $k_{9}$ or directly from the singlet radical ion pair state ${ }^{1}\left(\right.$ Dimer $\left.^{+} \cdots \mathrm{H}_{2} \mathrm{P}^{-}\right)$(Fig. 8). The reason of that may be connected with the fact that the spin-exchange energy is negligible and the spin rephasing (rate constant $k_{34}$ ) between the singlet and triplet radical ion pairs is rather effective [67]. It is interesting to note that multiporphyrin triads and pentads may be considered as very rare electronacceptor synthetic model systems [68-70] in which a single electron transfer step produces radical ion pairs at a short $(\sim 11 \AA)$ distance with a large exchange integral $J$ that leads to the efficient formation of locally excited $\mathrm{T}_{1}$-states.

\subsection{Interaction of triads and pentads with molecular oxygen}

Our next step was devoted to examine the interaction of multiporphyrin systems with molecular oxygen taking into account that only locally excited $\mathrm{S}_{1}$ - and $\mathrm{T}_{1}$-states of the extra-ligand subunit in triads and pentads play a dominant role in this process. The obtained steady-state and kinetic experimental data are collected in Table 3 . It is seen that at $293 \mathrm{~K}$ in degassed solutions, fluorescence quantum yields and lifetimes do practically not differ for all pyridyl substituted porphyrin free base derivatives. In addition, the experimental data on transient $\mathrm{T}-\mathrm{T}$ absorption (not presented in Table 3) show that in degassed TOL or $\mathrm{MCH}$ solutions at $293 \mathrm{~K} \mathrm{~T}_{1}$-state decays are practically the same $\left(\tau_{\mathrm{T}}^{0}=1.2-1.4 \mathrm{~ms}\right)$ for individual extra-ligands, triads and pentads. In the triads of $(\mathrm{ZnOEP})_{2} \mathrm{Ph} \otimes \mathrm{H}_{2} \mathrm{P}-\left(m^{\wedge} \mathrm{Pyr}\right)_{2}$-(iso- $\left.\mathrm{PrPh}\right)_{2}$ type, the $\mathrm{H}_{2} \mathrm{P}$ locally excited $\mathrm{T}_{1}$-state $\left(E_{\mathrm{T}}=1.44 \mathrm{eV}[63]\right)$ lies essentially lower than the CT-state (Fig. 8). Therefore in these triads the upper lying CT state does not influence the deactivation of the locally excited $\mathrm{T}_{1}$-state of the extra-ligand. From these

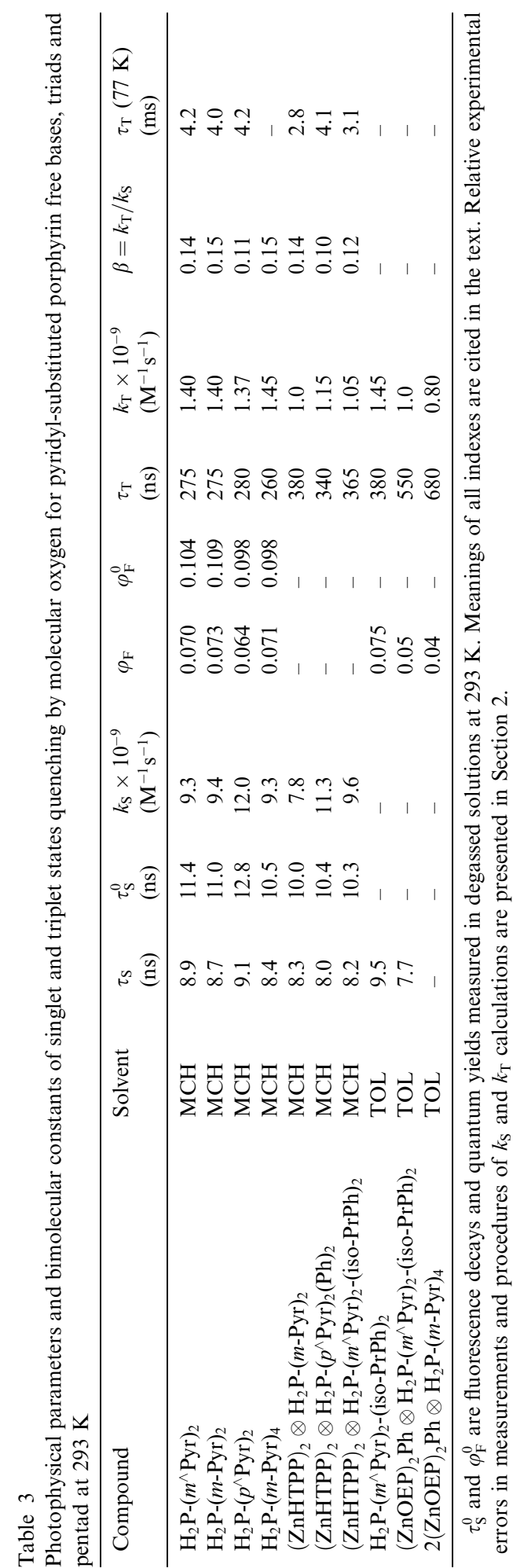




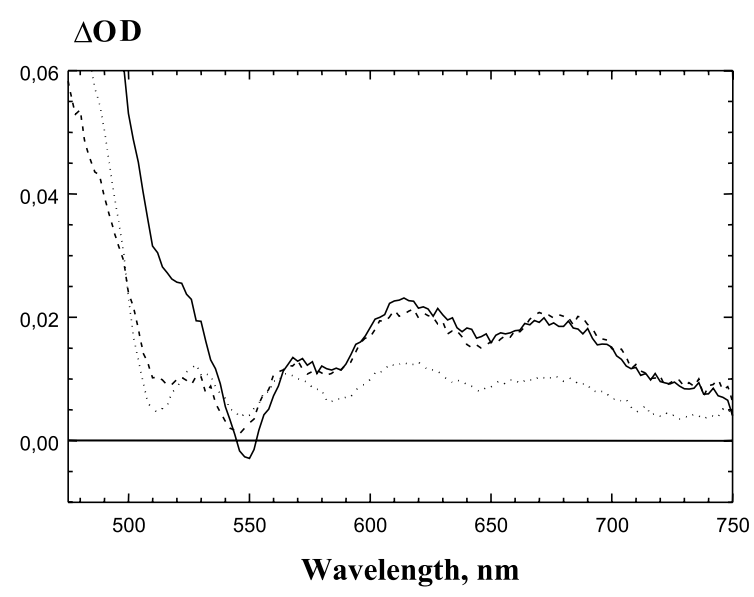

Fig. 9. Time-resolved transient absorption spectra of the triad $(\mathrm{ZnOEP})_{2} \mathrm{Ph} \otimes \mathrm{H}_{2} \mathrm{P}-\left(m^{\wedge} \mathrm{Pyr}\right)_{2}$-(iso- $\left.\mathrm{PrPh}\right)_{2}$ at delay times of $0.5 \mathrm{ps}(-), 6.0 \mathrm{ps}(--)$ and $4.5 \mathrm{~ns}(\cdots)\left(\lambda_{\mathrm{ex}}=400 \mathrm{~nm}\right.$, TOL, $293 \mathrm{~K})$.

photophysical backgrounds it may be concluded that the same situation is realised in the pentad $2(\mathrm{ZnOEP})_{2} \mathrm{Ph} \otimes \mathrm{H}_{2} \mathrm{P}-(m-\mathrm{Pyr})_{4}$ and in triads containing dimers (ZnHTPP $)_{2}$ or (ZnTPP $)_{2}$ [27].

It is seen also from Table 3 that the rate constants of $\mathrm{T}_{1}$-state deactivation are of the same order of magnitude for all extra-ligands at $77 \mathrm{~K}$ in rigid solutions. The comparison of $\tau_{\mathrm{T}}(77 \mathrm{~K})$ values obtained for the triads in rigid solutions with those found for the corresponding extra-ligands shows some deviations depending on the triad structure. In the case of the triad $(\mathrm{ZnHTPP})_{2} \otimes$ $\mathrm{H}_{2} \mathrm{P}-\left(p^{\wedge} \mathrm{Pyr}\right)_{2}$ no differences in $\tau_{\mathrm{T}}(77 \mathrm{~K})$ values were observed in comparison with $\mathrm{H}_{2} \mathrm{P}-\left(p^{\wedge} \mathrm{Pyr}\right)_{2}$. In contrast, for triads $(\mathrm{ZnHTPP})_{2} \otimes \mathrm{H}_{2} \mathrm{P}-(m-\mathrm{Pyr})_{2}$ and $(\mathrm{ZnHTPP})_{2} \otimes \mathrm{H}_{2} \mathrm{P}-\left(m^{\wedge} \mathrm{Pyr}\right)_{2} \quad$ a noticeable shortening of $\tau_{\mathrm{T}}(77 \mathrm{~K})$ values is detected with respect to those measures for the corresponding individual extra-ligands $\mathrm{H}_{2}-(m-\mathrm{Pyr})_{2}$, and $\mathrm{H}_{2} \mathrm{P}-$ $\left(m^{\wedge} \mathrm{Pyr}\right)_{2}$. Taking into account the structural properties of these triads (see Fig. 3) one should connect this tendency with $\pi-\pi$ interactions of the dimer and extra-ligand in the triads depending on their mutual geometry. In fact, it is seen from Fig. 3 that in the triad $(\mathrm{ZnHTPP})_{2} \otimes \mathrm{H}_{2} \mathrm{P}-\left(p^{\wedge} \mathrm{Pyr}\right)_{2}$ with a practically orthogonal arrangement of dimeric and extra-ligand subunits, the interaction of $\pi$-conjugated macrocycles is minimal, thus not manifesting in $\tau_{\mathrm{T}}(77 \mathrm{~K})$ shortening. At the same time, for the other triads with a smaller centre-tocentre distance between subunits, the overlap of $\pi$ conjugated macrocycles becomes essentially larger. In a result, an extra-ligand $\tau_{\mathrm{T}}(77 \mathrm{~K})$ shortening is observed in these arrays.

In the presence of oxygen, both $\mathrm{S}_{1}$ - and $\mathrm{T}_{1}$ states quenching is observed for all pyridyl substituted porphyrin free bases. Experimental values of bimolecular constants $k_{\mathrm{T}}$ are of the same order of magnitude with respect to those known for other porphyrin free bases [60]. It should be mentioned that for all compounds under consideration the ratio $\beta=k_{\mathrm{T}} / k_{\mathrm{S}}$ is within $0.11-0.15$. It corresponds to the spin-statistical factor of $g=1 / 9$ reflecting the situation $[41,57]$ where triplet states of the compounds are quenched by triplet molecular oxygen, ${ }^{3} \mathrm{O}_{2}$ (Scheme I).

The role of structural organisation of triads and pentads is most readily understood upon their interaction with molecular oxygen in liquid solutions at $293 \mathrm{~K}$. The comparative analysis of data summarised in Table 3 shows that both $k_{\mathrm{S}}$ and $k_{\mathrm{T}}$ values for extra-ligands in the triads are smaller than those obtained for the corresponding individual pyridyl substituted porphyrins. Additionally, the observed decrease of $k_{\mathrm{S}}$ and $k_{\mathrm{T}}$ constants depending on the triad structure is maximal for $(\mathrm{ZnHTPP})_{2} \otimes \mathrm{H}_{2} \mathrm{P}-(m-\mathrm{Pyr})_{2}$ and less pronounced for $(\mathrm{ZnHTPP})_{2} \otimes \mathrm{H}_{2} \mathrm{P}-\left(m^{\wedge} \mathrm{Pyr}\right)_{2}$ and $(\mathrm{ZnHTPP})_{2} \otimes$ $\mathrm{H}_{2} \mathrm{P}-\left(p^{\wedge} \mathrm{Pyr}\right)_{2}$. For all triads the ratio $\beta=k_{\mathrm{T}} / k_{\mathrm{S}}$ is the same with respect to that for the corresponding monomers. It means that the mechanism of oxygen induced quenching of extra-ligand excited states in the triads does not change (Scheme I). Recently, we have shown [30] that the existence of CT-states in the triads with pentafluorinated extraligand (strong electron acceptor) leads to this extra-ligand $\mathrm{T}_{1}$-state shortening (from $1.2 \mathrm{~ms}$ down to $6.4 \mu \mathrm{s}$ in degassed $\mathrm{MCH}$ at $293 \mathrm{~K}$ ). Nevertheless, in the presence of oxygen, pentafluorinated extra-ligand $\mathrm{T}_{1}$-state decay in the triad is $345 \mathrm{~ns}$ that is comparable with $\tau_{\mathrm{T}}=355 \mathrm{~ns}$ obtained for the triad of the same geometry containing usual pyridyl substituted extra-ligand. Therefore it is reasonable to connect the relative decrease of $k_{\mathrm{S}}$ and $k_{\mathrm{T}}$ values upon transition from monomeric extra-ligands to the triads with screening effects depending on the triad structure. 
In fact, the $\mathrm{Zn}$-porphyrin dimer in the triad (without any populated excited state) plays a screening role limiting the access of oxygen molecule to the excited extra-ligand. For the "opened" triad $(\mathrm{ZnHTPP})_{2} \otimes \mathrm{H}_{2} \mathrm{P}-\left(p^{\wedge} \mathrm{Pyr}\right)_{2}$ (see Fig. 3) this screening effect is minimal, and the measured decrease of $k_{\mathrm{T}}$ value for this triads is minimal with respect to that obtained for individual $\mathrm{H}_{2} \mathrm{P}-\left(p^{\wedge} \mathrm{Pyr}\right)_{2}$. In contrast, for "closed" triads, $(\mathrm{ZnHTPP})_{2} \otimes \mathrm{H}_{2} \mathrm{P}-\left(m^{\wedge} \mathrm{Pyr}\right)_{2}$ and $(\mathrm{ZnHTPP})_{2} \otimes$ $\mathrm{H}_{2} \mathrm{P}-(m-\mathrm{Pyr})_{2}$, the access of oxygen molecule to the excited extra-ligand becomes more limited thus resulting in more pronounced decrease of the observed $k_{\mathrm{S}}$ and $k_{\mathrm{T}}$ values in comparison with those found for the corresponding monomers. Consistent with this interpretation is the fact that for pentad $2(\mathrm{ZnOEP})_{2} \mathrm{Ph} \otimes \mathrm{H}_{2} \mathrm{P}-(m-\mathrm{Pyr})_{4} \quad$ where screening effects are higher with respect to those in triads, $\mathrm{T}_{1}$-state decay is longer (Fig. 10) and the relative decrease of $k_{\mathrm{T}}$ values is maximal in comparison with the triad at the same experimental conditions (see Table 3, experiments in TOL). Finally, quantum yields of singlet oxygen generation by triad $\left(\gamma_{\Delta}=0.8\right)$ and pentad $\left(\gamma_{\Delta}=0.7\right)$ are high in TOL and comparable with those known for monomeric free bases $\left(\gamma_{\Delta}=0.73\right.$ for OEP and 0.68 for TPP $[41,60])$. In fact, for triads or pentads it

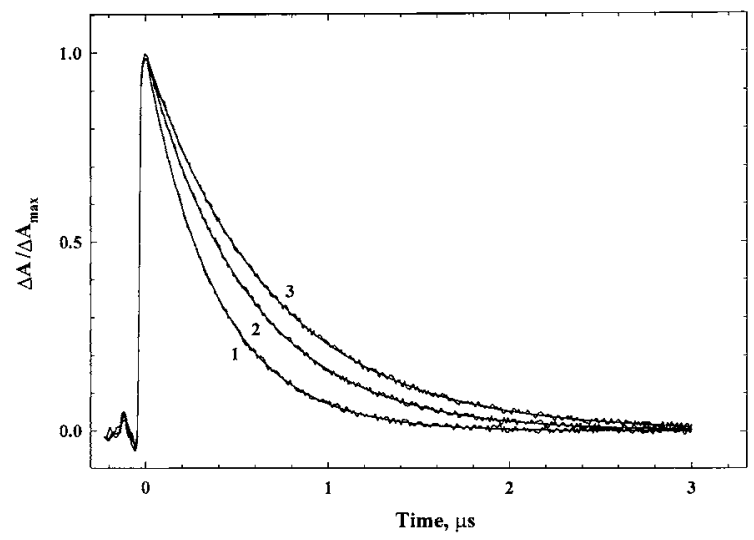

Fig. 10. Kinetic traces of transient triplet-triplet absorption changes for individual extra-ligand $\mathrm{H}_{2} \mathrm{P}\left(m^{\wedge} \mathrm{Pyr}\right)_{2}$-(iso- $\left.\mathrm{PrPh}\right)_{2}$ (1), triad $(\mathrm{ZnOEP})_{2} \mathrm{Ph} \otimes \mathrm{H}_{2} \mathrm{P}-\left(m^{\wedge} \mathrm{Pyr}\right)_{2}$-(iso- $\left.\mathrm{PrPh}\right)_{2}$ (2), and pentad $2(\mathrm{ZnOEP})_{2} \mathrm{Ph} \otimes \mathrm{H}_{2} \mathrm{P}-(m-\mathrm{Pyr})_{4}(3)$ in non-degassed TOL at $293 \mathrm{~K}$ formed by the excitation at $532 \mathrm{~nm}$ and measured at $440 \mathrm{~nm}$. means that the quenching of extra-ligands excited states by $\mathrm{O}_{2}$ takes place with the same efficiency practically like for monomers, but with smaller bimolecular constants because of screening effects. At last, the observation of singlet oxygen generation by triads and pentads in liquid solutions at room temperature serves the independent direct proof of the existence of locally excited triplet states in these arrays.

\section{Conclusions}

The photophysical properties of $\mathrm{Zn}$-porphyrin and $\mathrm{Zn}$-chlorin chemical dimers are sensitive to the extra-ligation by PYR. One of these properties is enhanced non-radiative $\mathrm{T}_{1} \leadsto \mathrm{S}_{0}$ intersystem crossing (the most pronounced for dimers with higher lying $\mathrm{T}_{1}$-states) relative to the uncomplexed dimers. The quenching is attributed to several reasons: accepting role of the extra-ligand vibrations, the enhanced spin-orbit coupling due to the singlet $\sigma, \pi^{*}$ states energy lowering and the out-ofplane distortion of porphyrin macrocycle. At 293 $\mathrm{K}$ for pyridinated dimers it was shown that their $\mathrm{T}_{1}$-states quenching by molecular oxygen depends on the spacer flexibility and donor-acceptor interactions with PYR.

Using twofold coordination of $\mathrm{Zn}$-porphyrin dimers by di- and tetrapyridyl substituted porphyrin extra-ligands, triads and pentads have been prepared. The co-operative existence of energy and electron transfer processes in these systems results in the population of the final locally excited $\mathrm{S}_{1}$ - and $\mathrm{T}_{1}$-states of porphyrin extra-ligands. The quenching of these states in triads and pentads by molecular oxygen is noticeably weakened with respect to that for individual pyridyl substituted porphyrins. This effect is explained by the screening action of a strongly quenched $\mathrm{Zn}$-porphyrin dimer subunit in triads and pentads limiting the access of oxygen molecule to the excited extra-ligand. These facts have to be taken into account upon the analysis of natural dark and photoinduced reactions with participation of supramolecular systems with oxygen (oxygenation and deoxygenation in haemoglobin, singlet oxygen generation in tissues and photodynamic therapy of cancer). 


\section{Acknowledgements}

This work was supported by the National Foundation for Basic Research of Belarus (grant no. Ph 99-104) and DFG Schwerpunktprogramm (SPP 470, Schr 231).

\section{References}

[1] C.A. Hunter, L.D. Sarson, Angew. Chem. Int. Ed. Engl. 33 (1994) 2313.

[2] M. Drain, K.C. Russell, J.M. Lehn, Chem. Commun. (1996) 337.

[3] J.A.I. Oksanen, E.I. Zenkevich, V.N. Knyukshto, S. Pakalnis, P.H. Hynninen, J.E.I. Korrpi-Tommola, Biochim. Biophys. Acta-Bioenergetics. 1321 (1997) 165.

[4] M.O. Senge, K.M. Smith, J. Chem. Soc., Chem. Commun. (1994) 923.

[5] R.V. Slone, J.T. Hupp, Inorg. Chem. 36 (1997) 5422.

[6] A.V. Chernook, U. Rempel, C. von Borczyskowski, E.I. Zenkevich, A.M. Shulga, Chem. Phys. Lett. 254 (1996) 229.

[7] H. Imahori, K. Yamada, E. Yoshizawa, T. Okada, Y. Sakata, J. Porphyrins Phthalocyanines 1 (1997) 55.

[8] G. Vaijayanthimala, V. Krishnan, J. Porphyrins Phthalocyanines 1 (1997) 17.

[9] H.-J. Kim, N. Bampos, J.K.M. Sanders, J. Am. Chem. Soc. 121 (1999) 8120.

[10] D.A. Offord, S.B. Sachs, M.S. Ennis, T.A. Eberspacher, J.H. Griffin, C.E.D. Chidsey, J.P. Collman, J. Am. Chem. Soc. 120 (1998) 4478.

[11] N. Kanayama, T. Kanbara, H. Kitano, J. Phys. Chem. B. 104 (2000) 271.

[12] J.R. Miller, C.D. Dorough, J. Am. Chem. Soc. 74 (1952) 3977.

[13] J.P. Collman, J.A. Brauman, T.J. Collins, B.I. Iverson, J.L. Sessler, J. Am. Chem. Soc. 103 (1981) 2450.

[14] V.V. Apanasovich, E.G. Novikov, N.N. Yatskov, R.B.M. Koehorst, T.J. Schaafsma, A. van Hoek, J. Appl. Spectrosc. 66 (1999) 613.

[15] D. Gust, T.A. Moore, A.L. Moore, H.K. Kang, J.M. DeGraciano, P.A. Liddell, G.R. Seely, J. Phys. Chem. 97 (1993) 13637.

[16] U. Rempel, B. von Maltzan, C. von Borczyskowski, Chem. Phys. Lett. 245 (1995) 253.

[17] H. Seki, M. Hoshino, H. Shizuka, J. Phys. Chem. 93 (1989) 3630.

[18] A.T. Gradyushko, M.P. Tsvirko, Optika i Spektroskopiya 31 (1971) 548.

[19] B.M. Dzhagarov, E.I. Sagun, Zh. Prikl. Spektr. 23 (1975) 285.

[20] V.N. Knyukshto, A.M. Shulga, E.I. Sagun, E.I. Zenkevich, J. Appl. Spectrosc. 65 (1998) 943.

[21] J.M. Berg, Y. Shi, Science 271 (1996) 1081.
[22] X. Hu, A. Damjanovic, T. Ritz, K. Shulten, Proc. Natl. Acad. Sci. USA 95 (1998) 5935.

[23] V. Sundstrom, T. Pullerits, R. van Grondele, J. Phys. Chem. B 103 (1999) 2327.

[24] K.E. McAuley, P.K. Fyfe, R.J. Cogdell, N.W. Isaacs, M.R. Jones, FEBS Lett. (2000) 285.

[25] X.J. Jordanides, G.D. Scholes, G.R. Fleming, J. Phys. Chem. B 105 (2001) 1652.

[26] A.V. Chernook, A.M. Shulga, E.I. Zenkevich, U. Rempel, C. von Borczyskowski, J. Phys. Chem. 100 (1996) 1918.

[27] U. Rempel, S. Meyer, B. von Maltzan, C. von Borczyskowski, J. Lumin. 78 (1998) 97.

[28] E.I. Zenkevich, A.M. Shulga, S.M. Bachilo, U. Rempel, J. von Richthofen, C. von Borczyskowski, J. Lumin. 76-77 (1998) 354.

[29] E.I. Zenkevich, S.M. Bachilo, A.M. Shulga, U. Rempel, A. Willert, C. von Borczyskowski, Mol. Cryst. Liq. Cryst. 324 (1998) 169.

[30] A. Willert, S. Bachilo, U. Rempel, A.M. Shulga, E.I. Zenkevich, Ch. von Borczyskowski, J. Photochem. Photobiol. A: Chem. 126 (1999) 99.

[31] K.M. Smith, G.M.F. Busset, M.J. Bushell, Bioorg. Chem. 9 (1980) 1.

[32] A.M. Shulga, G.V. Ponomarev, Khim. Geterotsik1. Soedin. 3 (1988) 339.

[33] G.V. Ponomarev, A.M. Shulga, Doklady Akad. Nauk SSSR 281 (1983) 365.

[34] E.I. Zenkevich, A.M. Shulga, A.V. Chernook, G.P. Gurinovich, J. Appl. Spectrosc. 45 (1985) 1310.

[35] G.P. Gurinovich, E.I. Zenkevich, E.I. Sagun, A.M. Shulga, Opt. Spectrosc. 56 (1984) 637.

[36] F.R. Longo, J.D. Finarelli, J.B. Kim, J. Heterocycl. Chem. 6 (1969) 927.

[37] R.G. Little, J.A. Anton, P.A. Loach, J.A. Ibers, J. Heterocycl. Chem. 12 (1975) 343.

[38] G.D. Egorova, V.N. Knyukshto, K.N. Solov'ev, M.P. Tsvirko, Optika i Spektrosk. 48 (1980) 1101.

[39] S.M. Bachilo, J. Photochem. Photobiol. A: Chem. 91 (1995) 111.

[40] S.L. Murrov, I. Carmichael, G.L. Hug, Handbook of Photochemistry, Marcel Deccer, New York, 1993, pp. 269278.

[41] B.M. Dzhagarov, E.I. Sagun, V.A. Ganzha, G.P. Gurinovich, Khim. Fiz. 6 (1987) 919.

[42] P.J. Spellane, M. Gouterman, A. Antipas, S. Kim, Y.C. Liu, Inorg. Chem. 19 (1980) 386.

[43] I. Tabushi, S. Kugimiya, J. Am. Chem. Soc. 108 (1986) 6926.

[44] U. Rempel, B. von Maltzan, C. von Borczyskowski, J. Lumin. 53 (1992) 175.

[45] I.V. Avilov, I.V. Filatov, E.I. Zenkevich, A.M. Shulga, Zh. Prikl. Spektrosk. 68 (2001) 16.

[46] E.I. Zenkevich, A.M. Shulga, A.V. Chernook, E.I. Sagun, G.P. Gurinovich, Khim. Fiz. 8 (1989) 842.

[47] G.P. Gurinovich, E.I. Zenkevich, A.M. Shulga, E.I. Sagun, A. Suisalu, Zh. Prikl. Spektrosk. 41 (1984) 446. 
[48] E.I. Zenkevich, A.V. Chernook, A.M. Shulga, E.I. Sagun, G.P. Gurinovich, Khim. Fiz. 8 (1989) 891.

[49] G.W. Robinson, R.P. Frosch, J. Chem. Phys. 38 (1963) 1187.

[50] W. Siebrand, J. Chem. Phys. 46 (1967) 440.

[51] A.T. Gradyushko, S.S. Dvornikov, V.N. Knyukshto, K.N. Solov'ev, Optika i Spektrosk. 45 (1978) 1097.

[52] S.S. Dvornikov, K.N. Solov'ev, M.P. Tsvirko, Biofizika. 24 (1979) 791.

[53] R.H. Clarke, S. Hotchandani, S.P. Jagannathan, R.M. Leblanc, Photochem. Photobiol. 36 (1982) 575.

[54] V.N. Knyukshto, E.I. Zenkevich, E.I. Sagun, A.M. Shulga, S.M. Bachilo, Chem. Phys. Lett. 297 (1998) 97.

[55] E.I. Sagun, V.A. Ganzha, B.M. Dzhagarov, A.M. Shulga, Khim. Fiz. 10 (1991) 477.

[56] E.I. Zenkevich, A.M. Shulga, A.V. Chernook, E.I. Sagun, G.P. Gurinovich, Proc. Indian Acad. Sci. 107 (1995) 795.

[57] O.L.J. Gijzeman, E. Kaufman, G. Porter, J. Chem. Soc. Farad. Trans. II. 69 (1973) 708.

[58] H. Levanon, A. Regev, P.K. Das, J. Phys. Chem. 91 (1987) 14.

[59] J. Andreasson, J. Kajanus, G. Martensson, B. Albinsson, J. Am. Chem. Soc. 122 (2000) 9844.

[60] V.A. Ganzha, G.P. Gurinovich, B.M. Dzhagarov, G.D. Egorova, E.I. Sagun, A.M. Shulga, Zh. Prikl. Spektrosk. 50 (1989) 618.
[61] V.G. Majranowski, in: N.S. Enikolopyan (Ed.), Porphyrins: Spectroscopy, Photochemistry, Applications, Nauka, Moscow, 1987, pp. 127-181.

[62] K.M. Kadish, L.R. Shiue, R.K. Rhodes, L.A. Bottomley, Inorg. Chem. 20 (1981) 1274.

[63] E.I. Zenkevich, S.M. Bachilo, A. Willert, U. Rempel, A.M. Shulga, Ch. von Borczyskowski, Mat. Sci. Eng. C 631 (2001) in press.

[64] M.R. Wasielewski, D.G. Johnson, M.P. Niemczyk, G.L. Gains III, M.P. O’Neil, W.A. Svec, J. Am. Chem. Soc. 112 (1990) 6482.

[65] B.M. Dzhagarov, E.I. Sagun, G.P. Gurinovich, Zh. Prikl. Spektrosk. 15 (1971) 476.

[66] J. Rodriguez, C. Kirmaier, D. Holton, J. Am. Chem. Soc. 111 (1989) 6500.

[67] D.D. Fraser, J.R. Bolton, J. Phys. Chem. 98 (1994) 1626.

[68] K. Hasharoni, H. Levanon, S.R. Greenfield, D.J. Gosztola, W.A. Svec, M.R. Wasielewski, J. Am. Chem. Soc. 118 (1996) 10228.

[69] D. Carbonera, M. Di Valentin, C. Corvaja, G. Agostini, G. Giacometti, P.A. Liddell, D. Kuciauskas, A.L. Moore, T.A. Moore, D. Gast, J. Am. Chem. Soc. 120 (1996) 4398.

[70] G.P. Wiederrecht, W.A. Svec, M.R. Wasielewski, T. Galili, H. Levanon, J. Am. Chem. Soc. 121 (1999) 7726. 